DHI Rom

\title{
Jahresbericht 2017
}

\begin{tabular}{ll} 
Allgemeines & \multicolumn{1}{l}{ Kooperationen } \\
$-\quad$ Strukturmaßnahmen und Profil- & - Zusammenarbeit innerhalb der \\
$\quad$ bildung & Stiftung \\
- Personalia & - Weitere Kooperationen \\
Daueraufgaben und Forschung & Historische und Musikgeschichtliche \\
Forschungsprojekte nach Epochen & Bibliothek \\
und Abteilungen & - Bestandserhaltung \\
Wissenschaftliche Datenverarbeitung & Nachwuchsförderung: Praktika und \\
Veranstaltungen & Stipendien \\
$-\quad$ Wissenschaftliche Tagungen und & Haushalt, Verwaltung \\
$\quad$ Workshops & Informations- und Kommunikations- \\
$-\quad$ Vortragsveranstaltungen & technologie \\
Publikationen & Personal und Gremien \\
$-\quad$ Institut & - Personal und Institutsaufgaben \\
$-\quad$ Institutsmitarbeiter/-innen & - Wissenschaftlicher Beirat \\
Vorträge, Lehre, Mitgliedschaf- & - Freundeskreis des DHI \\
ten und Auszeichnungen der & \\
Institutsmitarbeiter/-innen &
\end{tabular}

\section{Allgemeines}

\section{Strukturmaßnahmen und Profilbildung}

Ziel des Deutschen Historischen Instituts in Rom, wie auch der anderen Institute der Max Weber Stiftung, ist die Förderung und Durchführung geisteswissenschaftlicher Forschung im Ausland mit Blick auf die spezifischen Möglichkeiten und Herausforderungen von Standort und Gastland, in enger Anbindung an die deutsche Forschungs- und Universitätslandschaft. 2017 endete die erste, fünfjährige Amtsperiode des aktuellen Direktors. Sie war geprägt durch das Bemühen, dieses Ziel durch die Entfaltung des wissenschaftlichen Potentials des Instituts, v.a. in der Schärfung und weiteren Stärkung von Forschungsprofil und -agenda sowie in der Nachwuchsförderung und Vernetzung, zu erreichen. Mit dem Übergang in die zweite Amtszeit erscheint zunehmend als vordringliche Aufgabe, die Forschungskapazitäten des DHI, seine öffentliche Wirksamkeit und wissenschaftlichen Servicefunktionen durch einen möglichst optimalen und verantwortungsbewussten Ressourceneinsatz zu verbessern. Das betrifft interne Umstrukturierungen, weiterhin dringend anstehende, 
unumgängliche aufwändige Maßnahmen zur Bestandserhaltung der im Bundesbesitz befindlichen, nach Grundstücksumfang und Gebäudefläche mit Abstand größten Liegenschaft innerhalb der Stiftung sowie die Ausschöpfung der bislang nur unzureichend, zu Teilen inadäquat genutzten Möglichkeiten, die die Liegenschaft bietet.

Erster Schritt und Angelpunkt der Maßnahmen war im Berichtszeitraum auf der Grundlage einer vom Präsidenten des Stiftungsrats veranlassten, im April 2016 durchgeführten Evaluierung die organisatorische Zusammenlegung der beiden Bibliotheken des Instituts, die freilich die Sichtbarkeit und das Eigenprofil der Fachbestände, insbesondere im Bereich der Musikgeschichte sowie der historischen Sammelschwerpunkte und historischen Sondersammlungen, nicht beeinträchtigen wird. Diese Maßnahme erfolgt nicht isoliert, sondern ist eingebunden in ein übergreifendes Gesamtkonzept der Neustrukturierung und Modernisierung. Dieses Konzept wurde im Auftrag des Instituts von einem Architekten mit internationaler Expertise im Bereich wissenschaftlicher Bibliotheken und Einrichtungen in Form eines Masterplans ausgearbeitet, der auf einer ebenfalls 2018 erstmals erstellten umfassenden Dokumentation des Zustands der Liegenschaft und dem Abgleich des aktuellen Bestands mit den Zielen und Aufgaben des Instituts basiert. Der Plan formuliert, entsprechend diesen Zielen, einen Katalog von Maßnahmen zur Restrukturierung der Liegenschaft und wurde im November 2017 vom Stiftungsrat zustimmend zur Kenntnis genommen. Auf seiner Grundlage wird mit dem BMBF über die Finanzierung und Umsetzung der Maßnahmen verhandelt.

Ein internes Seminar im Mai diente der weitergehenden Profilierung am Institut: Ausgehend von ihren jeweiligen eigenen Disziplinen und Forschungen diskutierten die Wissenschaftler/-innen des DHI über Möglichkeiten, die epochen- und disziplinenübergreifende Verständigung, insbesondere über Theorie- und Methodenfragen, im Haus selbst zu fördern und zugleich Kriterien zu Anschluss und Vermittlung der Forschungen nach außen, auch zur Strukturierung und Priorisierung von Kooperationen, zu formulieren. Insbesondere zwei Bereiche, die traditionelle Felder mit neuen Fragestellungen verschränken und in denen bereits während der letzten Jahre entscheidende Impulse für das Forschungsprofil des Instituts gesetzt wurden, wurden hier hervorgehoben: zum einen der Bereich der Religion, in dem sich klassische Themen, v. a. der Kirchen- und Papstgeschichte, mit neuen Ansätzen z. B. in Institutionen-, Theologie- und Ideengeschichte, sozial- und kulturgeschichtlichen Perspektiven der Katholizismusforschung sowie der Geschichte von Christentum und Judentum verbinden; zum anderen vom Standort des Instituts aus gesehen besonders relevante Raumbegriffe wie Mittelmeer, Südeuropa und Mezzogiorno. Hier geht es um Prozesse des Mental Mapping, um die in diesen Konzepten enthaltenen Bilder, Werte und Hierarchien, um Vorstellungen von Zentralität und Peripherie, aber auch um die Ableitung von raum- bzw. regionenbezogenen Forschungsagenden sowie um Grenzen, Kontakt- und Austauschzonen. In diesen Bereich fallen ebenso die Geschichte der Stadt Rom im Besonderen und stadthistorische Forschungen, insbesondere zu Städten des „Südens“, im Allgemeinen. In beiden Feldern, von Religion und Raum, spielen 
vergleichende und beziehungsgeschichtliche, transregionale und transnationale Perspektiven und Ansätze, die die überkommene, seit der Nachkriegszeit dominierende binationale Ausrichtung des Instituts erweitern und neu ausrichten, eine herausragende Rolle. Als Achse, die in vielen der am Institut durchgeführten Forschungsprojekte zum Tragen kommt, wurde schließlich Macht als zentrale Dimension in sozialen, politischen und kulturellen Beziehungen bzw. Beziehungsgefügen hervorgehoben.

Im Berichtzeitraum wiesen besonders viele Aktivitäten religionsgeschichtliche Bezüge auf. Im Zeichen der Lutherdekade standen zwei historische Veranstaltungen: eine internationale Tagung, die sich mit der Rezeption Luthers in Italien im 16. Jahrhundert insbesondere aus buch- und wissensgeschichtlicher Perspektive beschäftigte, sowie die mit dem DHI vertreten durch seinen Mitarbeiter Andreas Rehberg ausgerichtete internationale Tagung der Willibald-Pirckheimer-Gesellschaft zum Thema „Ulrich von Hutten und Rom. Deutsche Humanisten in der Ewigen Stadt am Vorabend der Reformation“. Die Musikgeschichtliche Abteilung widmete ihre Reihe „Musicologia oggi“ dem Thema „Klangbild Reformation“ mit vier Vorträgen von Musikwissenschaftler/-innen und Komponisten. Ein Studientag in Zusammenarbeit mit deutschen und italienischen Partnern untersuchte das Wirken von Daniel Ernst Jablonski, eines eng mit Leibniz verbundenen lutherischen Theologen, und dessen weit gespannten europäischen Gelehrtennetzwerke. Überdies wurde im Institut eine Ausstellung zu Jablonski gezeigt. In einer deutsch-belgischen Kooperation mit dem DHI wurde von Andreea Badea ein interdisziplinärer Workshop zum Thema „Making Truth - Administrating Truth. Establishing Credibility in Early Modern History“ ausgerichtet, in dem wissenschafts- und wissensgeschichtliche mit religionsgeschichtlichen Fragestellungen zusammengeführt wurden. Einen Höhepunkt in den Aktivitäten des Berichtzeitraums stellte die in Zusammenarbeit des DHI, wiederum vertreten durch Andreea Badea, mit der École française de Rome, dem Istituto Svizzero di Roma und der Universität Bern organisierte internationale Tagung „Going Native or Remaining Foreign? Catholic Missionaries as Local Agents in Asia (17th to 18th Centuries)“ dar, in der Verhalten und Spielräume katholischer Missionare in Asien gemäß unterschiedlicher sozialer Umgebungen, ob Hof, Stadt oder ländlicher Raum, untersucht wurden. Religionsgeschichtliche Implikationen hatte der Abschlussworkshop des DFG-Netzwerks „Gender - Nation - Emancipation. Women and Families in the ,long“ Nineteenth Century in Italy and Germany“ als Fortführung einer ebenfalls am DHI im Vorjahr organisierten Veranstaltung, in dem die vorgeblich parallele Entwicklung der beiden „verspäteten“ Nationen Italien und Deutschland im Hinblick auf die jüdische Geschichte hinterfragt wurde. Aus einer Kooperation von Theologen/-innen deutscher Universitäten und dem DHI erwuchs eine Tagung in Form eines internationalen Fachgesprächs zum Thema „Menschenrechte in der katholischen Kirche“, in dem das spannungsvolle Verhältnis der römischen Kirche zu den Menschenrechten in historischen, systematischen und praktischen Perspektiven diskutiert wurde.

Raumgeschichtliche Fragestellungen standen im Zentrum zweier Veranstaltungen: In einem interdisziplinären Workshop des italienisch-schwedischen For- 
schungsprojektes „Spaces of Expectation“ in Zusammenarbeit mit dem DHI „Semantics of Space“, in dem neben Historikern des Instituts auch die Musikgeschichtliche Abteilung prominent beteiligt war, wurden unterschiedliche Raumkonzepte vor dem Hintergrund begriffsgeschichtlicher Ansätze untersucht. Auf einer Tagung der DFGForschergruppe „Urbane Ethiken“, ebenfalls in Kooperation mit dem DHI wurden internationale Fallstudien zum Thema „Ethische Debatten und urbane Praxen“ zur Diskussion gestellt.

Einen Höhepunkt der Veranstaltungen der Musikgeschichtlichen Abteilung, vertreten durch Sabine Ehrmann-Herfort und die Projektmitarbeiterin Chiara Pelliccia, stellte ein Workshop des von der Leibniz-Gemeinschaft getragenen, am Leibniz-Institut für Europäische Geschichte in Mainz angesiedelten internationalen Verbundprojekts zu „Repräsentationen des Friedens im vormodernen Europa“ zum Thema „Musica e pace. Nuove ricerche sull'Età moderna“ dar, in dessen Rahmen ein öffentliches Konzert mit Friedenskompositionen des 15. bis 18. Jahrhunderts veranstaltet wurde. Den 450. Geburtstag von Claudio Monteverdi beging das Institut mit einem Festvortrag von Silke Leopold (Heidelberg) und der Präsentation des italienisch-japanischen Projekts „Japan Orfeo“ (Kamakura/Tokyo 2016) durch die beiden Initiatoren, den Dirigenten und Musikwissenschaftler Aaron Carpenè (Rom) und den Opernregisseur Stefano Vizioli (Rom/Pisa). Im Bereich der Zeitgeschichte standen, entsprechend der über lange Zeit aufgebauten Expertise des Instituts, Veranstaltungen aus dem Themenbereich der Geschichte von Faschismus, Nationalsozialismus und des Zweiten Weltkriegs im Mittelpunkt, so u.a. in zwei von Lutz Klinkhammer betreuten Veranstaltungen, einem interdisziplinären Studientag zum Umgang mit Geisteskranken im Nationalsozialismus und Faschismus sowie einem Workshop zur italienischen und spanischen Engagement am Vernichtungskrieg gegen die Sowjetunion. Für die Zeitgeschichte ist überdies eine von der Gastwissenschaftlerin Nicole Kramer ausgerichtete internationale Tagung zur Geschichte des italienischen Sozialstaats in vergleichender und beziehungsgeschichtlicher Perspektive besonders hervorzuheben.

Vornehmlich an die wissenschaftliche Öffentlichkeit der Stadt Rom richtete sich eine Reihe von Abendvorträgen renommierter Referent/-innen, so von Irmgard Fees (München) als Mitglied des Beirats mit dem Jahresvortrag und Sible de Blaauw (Nijmegen) mit dem Vortrag des Freundeskreises des DHI sowie Joachim Bahlcke (Stuttgart), Heiner Bielefeldt (Erlangen-Nürnberg), Christoph Cornelißen (Frankfurt), Paul F. Grendler (Toronto), Ralf Hoyer (Berlin), Axel Körner (London), Siegfried Matthus (Berlin), Daniele Menozzi (Pisa), Diana Mishkova (Sofia), Silke Leopold (Heidelberg), Christoph Neumann (München), Irmgard Scheidler (Würzburg) und Thomas Schmidt (Manchester). Lebhaften Zuspruch des Publikums ernteten auch die „Kinolektionen“, im Berichtsjahr organisiert von Heinrich Lang zu einer deutsch-italienischen Koproduktion von 1937, dem Historienfilm „Condottieri“ mit Luis Trenker, der zugleich als Regisseur firmierte, in der Hauptrolle, sowie einem frühen Musikfilm mit Enrico Caruso in einer Doppelrolle, der US-Produktion „My Cousin“ von 1918, der von Richard Erkens vorgestellt wurde. 


\section{Personalia}

Folgende Wechsel im Personal waren im Berichtzeitraum zu verzeichnen: Heinrich Lang, Fellow im Bereich der Frühneuzeit, sowie die Gastwissenschaftlerin Nicole Kramer kehrten im Sommer an ihre Heimatuniversitäten Bamberg und Frankfurt am Main zurück. Im Sommer endete auch die Tätigkeit von Carlo Taviani am DHI, der nach Fertigstellung eines Buchmanuskripts zum Thema „Origins of the Corporations. The Casa di San Giorgio and its Fortune in Northern Europe (1446-1720)“ als Research Associate an die Villa I Tatti - The Harvard University Center for Italian Renaissance Studies wechselte, jedoch im Rahmen seines Projekts zu den Netzwerken genuesischer Kaufleute und den Anfängen des Kapitalismus weiterhin mit dem Institut kooperiert. Amedeo Osti Guerrazzi beendete seine Arbeit am „Dienstkalender Benito Mussolinis“ im Juni und kooperiert ebenfalls weiterhin als Mitarbeiter der Fondazione Museo della Shoa di Roma mit dem DHI. Auf Nicole Kramer folgte als Gastwissenschaftler im Oktober Daniel Hedinger (München), der ein Projekt zur Geschichte des Zweiten Weltkriegs aus transimperialer und (post)kolonialer Perspektive bearbeitet. Ebenfalls im Oktober nahm Christian Neumann, von der Universität Heidelberg kommend, seine Tätigkeit als wissenschaftlicher Mitarbeiter im Bereich der mittelalterlichen Geschichte mit einem Projekt zum Thema „Alte Herrscher des Mittelalters. Könige, Dogen und Päpste“ auf, das als Beitrag zu einer „gerontologischen Mediävistik“ konzipiert ist. Im April bzw. September begannen die Doktorandinnen Franziska Rohloff, die bereits seit April 2016 mit einer Anschubfinanzierung der Max Weber Stiftung wichtige Vorarbeiteten geleistet hatte, und Dorothea Wohlfarth, finanziert durch das Auswärtige Amt, in einer von der Max Weber Stiftung und dem AA gemeinsam getragenen Kooperation die Arbeit an einem Projekt zur Geschichte der in Rom ansässigen deutschen Forschungsund Kulturinstitute 1918-1962, das zusammen mit der Bibliotheca Hertziana und der Villa Massimo durchgeführt wird. Im November nahm Angela Steinsiek, gefördert durch die DFG, die Arbeit an einer Edition der Briefe von Ferdinand Gregorovius auf.

\section{Daueraufgaben und Forschung}

Die institutionellen Daueraufgaben werden zum Großteil von den festangestellten Wissenschaftlern/-innen des Instituts getragen, aufgeteilt $u$. a. nach jeweiligen Epochenzuständigkeiten. Dazu gehören insbesondere die Betreuung der Publikationen des Hauses, die Beratung des wissenschaftlichen Nachwuchses, vor allem der Stipendiaten/-innen und der Praktikanten/-innen, die Hilfe und Unterstützung bei Forschungen in vatikanischen und italienischen Archiven und Bibliotheken sowie die Bereitstellung wissenschaftlicher Expertise für Forschung, Medien und Politik. Im Berichtszeitraum wurde der Bereich der Publikationen neu strukturiert. $\mathrm{Zu}$ den entsprechenden Maßnahmen gehörten insbesondere die Übergabe der redaktio- 
nellen Betreuung der Reihe „Ricerche dell'Istituto Storico Germanico di Roma“ an Andreas Rehberg sowie die Einbeziehung aller wissenschaftlichen Mitarbeiter/-innen in die Planungen für den Beitrags- und Rezensionsteil der Institutszeitschrift. Ebenso wurde ein institutsinterner Arbeitskreis „Publikationen“ gegründet, der sich zum Zweck der Koordination und weiterer Planung regelmäßig trifft und aus dem Direktorium, den wissenschaftlichen Mitarbeiter/-innen und den Redakteuren besteht. 2017 wurde der erste Band der „Online-Schriften des DHI Rom. Neue Reihe / Pubblicazioni online del DHI Roma. Nuova serie“ publiziert, die, ebenso wie die historische Schriftenreihe „Bibliothek des Deutschen Historischen Instituts Rom“, von Kordula Wolf, der Referentin für das frühe und hohe Mittelalter, betreut wird. Kordula Wolf war weiterhin zusammen mit Claudia Gerken mit dem Aufgabenbereich der Öffentlichkeitsarbeit betraut. Ihre Forschungen bezogen sich auf die christlich-muslimischen Beziehungen im frühmittelalterlichen Unteritalien, in deren Kontext sie $u$. a. ein neues Projekt zu Küstenregionen des Patrimoniums Petri vorbereitet. Andreas Rehberg, Referent für das Spätmittelalter, trat mit der Übernahme der Betreuung der RicercheReihe seine Zuständigkeit für das Repertorium Germanicum an Jörg Voigt, zugleich Projektbearbeiter des Repertorium, ab. Weiterhin ist A. Rehberg für das historische Institutsarchiv zuständig und beteiligt sich an der Organisation des Circolo Medievistico Romano. Seine Forschungen konzentrieren sich insbesondere auf Fragen der stadtrömischen Geschichte sowie der Heraldik in Rom. In die Zuständigkeit von Alexander Koller als Referent für die Frühe Neuzeit fallen die Arbeiten an der Edition der frühneuzeitlichen Nuntiaturberichte aus Deutschland, die er zusammen mit der Publikation der päpstlichen Hauptinstruktionen koordiniert. Im Berichtzeitraum konnte er aufgrund einer schweren Erkrankung, deren Behandlung sich bis zum Jahresende hinzog, nur stark eingeschränkt und phasenweise wissenschaftlich arbeiten. Mit der Ernennung zum stellvertretenden Direktor zunächst für vier Jahre nahm Lutz Klinkhammer seit März 2017 an der Arbeit der Leitungsebene des DHI teil. Als Referent für die Geschichte des 19. und 20. Jahrhunderts betreute er weiterhin die Bibliographischen Informationen zur neuesten Geschichte Italiens sowie Institutsprojekte wie die digitale Edition des Dienstkalenders Benito Mussolinis (1923-1945). Bei Tagungen, Anfragen und Veranstaltungen war er mit seiner Expertise im Feld der deutsch-italienischen Zeitgeschichte gefragt. Er beriet auch 2017 wieder bei der Umsetzung der den Außenministern Deutschlands und Italiens 2012 überreichten Empfehlungen der Deutsch-Italienischen Historikerkommission. Markus Engelhardt leitet die Musikgeschichtliche Abteilung und ist auch nach der im Berichtzeitraum erfolgten Zusammenlegung der Institutsbibliotheken mit Aufgaben im Bereich der musikhistorischen Bestände betraut. Zusammen mit Sabine Ehrmann-Herfort teilt er sich die Verantwortung für die beiden Publikationsreihen der Musikgeschichtlichen Abteilung. Sabine Ehrmann-Herfort arbeitete zur musikalischen Begriffsgeschichte sowie zur barocken Festkultur. Sie betreut und koordiniert das Forschungsvorhaben der Musikgeschichtlichen Abteilung im Rahmen des Mainzer Leibniz-Projekts zu Friedensrepräsentationen im vormodernen Europa. 
Im Bereich der Langzeitvorhaben der historischen Grundlagenforschung wurde im Zuge der Schlussphase der Erstellung von Band X des „Repertorium Germanicum“ zum Pontifikat Sixtus' IV., dessen Fertigstellung 2018 erfolgen wird, das Bearbeiterteam unter Leitung von Jörg Voigt neu organisiert, der zugleich die Arbeiten zu Band XI zum Pontifikat Innozenz' VIII. entscheidend voranbrachte und zur mittelalterlichen Frömmigkeitsgeschichte forschte.

\section{Forschungsprojekte nach Epochen und Abteilungen}

Einen wesentlichen Bestandteil der Forschungen stellen Projekte von Nachwuchswissenschaftler/-innen dar, die in der Regel eine berufliche Zukunft an deutschen Universitäten anstreben. Auch Forschungen von Wissenschaftler/-innen aus dem Gastland werden in zunehmendem Maß an das Haus angebunden. Folgende Einzelprojekte haben die Tätigkeiten am römischen DHI im Berichtszeitraum besonders geprägt.

\section{Mittelalter}

Dr. Christian Alexander Neumann (ab 1.10. 2017)

Alte Herrscher des Mittelalters: Könige, Dogen und Päpste. Ein Beitrag zu einer gerontologischen Mediävistik

\section{Projektbeschreibung}

Das Projekt untersucht die Altersphase mittelalterlicher Herrscher komparatistisch aus interdisziplinär mediävistisch-gerontologischer Perspektive. Dabei sollen die drei bisher weitgehend getrennten Forschungsfelder der mediävistischen Altersforschung und Königtumsforschung sowie der modernen Gerontologie in Fallstudien zu den Königen von England, zu venezianischen Dogen und Päpsten zusammengeführt werden. Die Analyse erfolgt in drei Perspektiven oder Dimensionen: In der diskursiven Dimension werden Repräsentationen alter Herrscher in antiken Darstellungen, der Bibel und theologischen Traktaten, der mittelalterlichen Literatur, Fürstenspiegeln sowie medizinischen Traktaten untersucht. Diese bilden das Wissensspektrum, das sich in konkreten Darstellungen narrativer Quellen in der diskursiv-praxeologischen Dimension manifestiert. Inwieweit textbasierte Repräsentationen alter Herrscher von diskursiven Normen und Idealen durchdrungen sind, stellt hier die grundlegende Fragestellung dar. In einem dritten Schritt wird das konkrete herrscherliche Agieren in der praxeologischen Dimension in den Blick genommen, so der königliche Hof und Haushalt, die sozialen Netzwerke (Söhne, Ehefrauen, Ratgeber), die Regelungen der Sukzession, die Verfassungs- und Verwaltungsstrukturen, der Körper des Herrschers, die herrscherlichen Aufgaben, der Aktionsradius sowie Krankheiten. Es 
wird zu ergründen sein, inwieweit all diese Bereiche von Kontinuitäten und Diskontinuitäten gekennzeichnet waren.

\section{Arbeitsschwerpunkte im Berichtszeitraum}

Mit der Bearbeitung des Projekts am DHI wurde im Oktober 2017 begonnen. In einem ersten Schritt erfolgte eine eingehende Einarbeitung in die gerontologische Forschungsliteratur. Weiterhin wurden die Einleitung und das Theoriekapitel in einer ersten Version verfasst und dabei klar herausgearbeitet, welche Ansätze und Theorien noch vertieft werden sollen. Darüber hinaus wurde das Thema „Alter und Klerus“ für einen Vortrag im Rahmen der RG-Tagung am DHI „Kuriale Quellen und Digital Humanities“ im März 2018 erarbeitet.

\section{Frühe Neuzeit}

\section{Dr. Andreea Badea}

Wahrheitsbegriffe im frühneuzeitlichen historischen Diskurs im Kontext von Kanon und Zensur

\section{Projektbeschreibung}

Das Projekt setzt sich mit katholischer Geschichtsschreibung als gelehrter und als aus dem kurialen System extrapolierter Verwaltungspraxis auseinander. In Anlehnung an Eric Hobsbawms Traditionsforschung sowie an die Studien von Steven Shapin zur Erzeugung von Glaubwürdigkeit im gelehrten Diskurs werden die Praktiken untersucht, derer sich diverse kuriale Kreise bedienten, um die katholische Geschichtsschreibung unter ständiger Arbeit am eigenen Entwurf vom römischen Universalismus zu regulieren, zu kanalisieren und bisweilen sogar zu ignorieren.

\section{Arbeitsschwerpunkte im Berichtszeitraum}

Die Quellenerschließung in den römischen Archiven ist weitestgehend beendet. Erste substanzielle Teile der Studie konnten verschriftlicht werden. Ausgehend von dem von der Projektbearbeiterin auf dem Historikertag 2016 ausgerichteten Panel „Wahrheit schaffen - Wahrheit verwalten“ wurde ferner ein internationaler Workshop organisiert, der es erlaubte, theoretische und methodische Ansätze des Projektes in einem größeren Rahmen zu diskutieren.

Ein weiterer Arbeitsschwerpunkt jenseits des Projektes beinhaltet die Vorbereitung der Selbstdarstellung des DHI Rom anlässlich der 2018 anstehenden Evaluierung.

\section{Projektrelevante Vorträge}

- Vortrag: „Cerco di stabilire, e di ordinare, per me, e per altrui la verità delle istorie“. Francesco Bianchini zwischen Gelehrsamkeit und Ämterjagd. Tagung 
„Gelehrte Praktiken in der Erforschung der Vergangenheit in der Frühen Neuzeit“, Hamburg 25. 3.

- Vortrag: The Roman Church and its Practices of Knowledge Control. Workshop Descartes Theme Group „Borders and the Transfer of Knowledge“, Utrecht 16. 6.

- Vortrag: Wahrheitsanspruch und Wissensautorität. Rom und die katholische Historiographie im Zeitalter der Kritik. Kolloquium der Lehrstühle für Mittelalterliche Geschichte und Geschichtliche Landeskunde, Universität Trier 12. 7.

- Vortrag: Für wen zensiert wird. Die Indexkongregation und ihr Anspruch auf Autorität gegen die „superbia di certi cervelli“. Kolloquium des Lehrstuhls für Geschichte der Frühen Neuzeit, Universität Tübingen 27. 11.

- Einleitung: Making Truth - Administrating Truth. Establishing Credibility in Early Modern History. Tagung „Making Truth - Administrating Truth. Establishing Credibility in Early Modern History“, DHI Rom 15. 11.

- Vortrag: Defining Past and Present - Hagiographical Debates and Historical Criticism in 17th Century Rome. Tagung „Making Truth - Administrating Truth. Establishing Credibility in Early Modern History“, Academia Belgica di Roma 16. 11.

Dr. Carlo Taviani (bis 15. 9. 2017)

Revising the Financial Corporation. Institutional Innovation and Knowledge Transfer in the Mediterranean (14th-16th centuries)

\section{Projektbeschreibung}

Das finanz- und wirtschaftsgeschichtliche Projekt untersucht mit einem kultur- und institutionengeschichtlichen Ansatz die Genueser Casa di San Giorgio im 15. und 16. Jahrhundert sowie die Netzwerke Genueser Händler mit Afrika und der Neuen Welt als Medium institutioneller Innovationen.

\section{Arbeitsschwerpunkte im Berichtszeitraum}

Das Buchmanuskript „Origins of the corporations. The Casa di San Giorgio and its Fortune in Northern Europe (1446-1720)“ wurde fertig gestellt. Eine erste Version wird in Kürze auf Italienisch erscheinen. Eine englische Publikation ist in Vorbereitung. Weiterhin wurde in Ergänzung und Fortführung des am DHI bearbeiteten Vorhabens zum Transfer ökonomischer Institutionen ein Folgeprojekt zu Netzwerken genuesischer Kaufleute zwischen Afrika und der Neuen Welt im 15. und 16. Jahrhundert begonnen, das in einer vom Bearbeiter, seit September 2017 Research Assistant an der Villa I Tatti Fiesole, geleiteten internationalen Forschergruppe mit drei Doktoranden/-innen, einem Postdoc und einem Archivar in Kooperation mit dem DHI durchgeführt wird.

\section{Projektrelevante Vorträge und Publikationen}

- Vortrag: Genoese Merchant Networks in Africa and America (15th-16th Centuries). Internationale Tagung „Crossroads Africa: Networks and Global Exchange (1250-1750)“, Villa I Tatti, Fiesole 12. 1. 
- Vortrag: In the Shadow of Other Empires: Genoese Merchant Networks and their Conflicts across the Atlantic Ocean (ca. 1450-1530). Internationale Tagung „Conflicts and their Resolution in Atlantic Europe (13th-17th Centuries)“, Universidad de La Laguna, Tenerife 21. 4.

- Vorlesung: The Genoese Slave Trade (15th-16th Centuries). University of Newcastle (Australien) 18. 8.

- Vortrag (mit S. Teasdale): Genoese Merchant Networks from the Black Sea to West Africa and the Americas (15th-16th Centuries). International ENIUGH Conference, Budapest 30. 8 .

- Il Banco genovese di San Giorgio prima Corporation?, in: A. Giardina/E. Betta/ M. P. Donato/A. Feniello (Hg.), Storia mondiale dell'Italia, Roma-Bari 2017, S. 357361.

- A Privatized State: Discourses on the Bank of San Giorgio (1446-1562), in: D. Bornstein/L. Gaffuri/B. J. Maxson (Hg.), Language of Power in Italy (1300-1600), Turnhout 2017, S. 49-64.

- La Casa de San Giorgio de Génova y los orígenes de las corporations europeas en la Edad Moderna, in: M. Herrero Sánchez (Hg.), Repúblicas y republicanismo en la Europa moderna (siglos XVI-XVIII), México D. F. 2017, S. 507-528.

- The Genoese Casa di San Giorgio as a Micro-Economic and Territorial Nodal System, in: W. Blockmans/M. Krom/J. Wubs-Mrosezwicz (ed.), The Routledge Handbook of Maritime Trade Around Europe 2017, S. 177-192.

PD Dr. Heinrich Lang (bis 30. 8. 2017)

Frühneuzeitliche Staatsbankrotte. Akteurszentrierte Analyse der europäischen Kreditmärkte um 1550

\section{Projektbeschreibung}

Das Projekt untersucht unter besonderer Berücksichtigung italienischer Archivquellen, aus dem Archivio Salviati in Pisa sowie der Biblioteca Apostolica Vaticana, die Insolvenzen der spanischen und der französischen Krone 1557/59 aus der Perspektive der an den Wechsel- und Kreditmärkten aktiven Bankiers.

\section{Arbeitsschwerpunkte im Berichtszeitraum}

Während des Aufenthaltes am DHI in Rom wurden zwei neue Forschungsprojekte konzipiert. Das erste Projekt in Kooperation mit Carlo Taviani ist ausgerichtet auf die Transferprozesse im Mittelmeerraum zwischen Europa, Asien und Afrika im globalen Zusammenhang. Zwei Dimensionen sollen zusammengeführt werden: die Objektgeschichte (Material Culture) und die handlungsorientierte Dimension. Den methodisch-theoretischen Hintergrund bilden dabei zwei antagonistisch gelagerte Ansätze: der von Carlo Taviani verfolgte Ansatz der „Implementation of Institutions“ und der Ansatz der historischen Praxeologie. Das zweite Projekt beschäftigt sich mit der persönlichen Buchführung und der „Finanzgeschichte eines Privatmannes“ am Beispiel 
des Florentiner Patriziers Alamanno di Iacopo Salviati; das Material hierfür liegt vor allem in den beiden Salviati-Archiven (Scuola Normale Superiore di Pisa und Biblioteca Apostolica Vaticana).

\title{
Projektrelevante Vorträge und Publikationen
}

- Vortrag: Warum Bankiers Herrscher finanzieren. Staatsbankrotte, Wechsel- und Kreditmärkte um 1550. Oberseminar, Georg-August-Universität Göttingen 31. 1.

- Projektvorstellung: Beiratssitzung, DHI Rom 4. 3.

- Projektvorstellung: Mittwochsvortrag, DHI Rom 26. 4.

- Vortrag: Italienische Kaufmannbankiers und die Bankrotte der Könige. Finanzmärkte Europas im 16. Jahrhundert. Goethe-Universität, Frankfurt am Main 2. 5.

- Wissensdiskurse in der ökonomischen Praxis. Kaufmannbankiers als Experten der Märkte im 16. Jahrhundert, in: M. Füssel/P. Knäble/N. Elsemann (Hg.), Wissen und Wirtschaft. Expertenkulturen und Märkte vom 13. bis zum 18. Jahrhundert, Göttingen 2017, S. 141-168.

\section{Neueste Geschichte}

\section{Dr. Carolin Kosuch}

Moderne, Nation und Tod. Eine deutsch-italienische Kulturgeschichte der Feuerbestattung im 19. Jahrhundert

\begin{abstract}
Allgemeine Projektbeschreibung
Das Projekt untersucht die wenig erforschte Frühzeit der Feuerbestattungsbewegung in Italien und Deutschland bis zum Ersten Weltkrieg. Im Fokus der vergleichenden und beziehungsgeschichtlichen Studie stehen Fragen der Genese, konflikthaften Verbreitung und Umsetzung der Idee und der Praktiken der Kremation. Dabei werden insbesondere wissenschaftsgeschichtliche Aspekte mit kultur- und emotionsgeschichtlichen Fragestellungen und Zugangsweisen verknüpft.
\end{abstract}

\section{Arbeitsschwerpunkte im Berichtszeitraum}

Im Berichtsjahr stand die Weiterentwicklung des Forschungsprojektes zur Feuerbestattung im Mittelpunkt der Arbeit. Hierzu gehörten Archivbesuche und Bibliotheksrecherchen sowie die Auswertung von Archivmaterialien und Primärquellen: Die Archivrecherchen in Italien und Deutschland sind weitestgehend abgeschlossen, für den Sommer 2018 bleiben noch die Besuche der Feuerbestattungsarchive in Durham und in Genf und einige wenige Konsultationen römischer Archive. Die Arbeit wird von Rebekka Habermas betreut und an der Universität Göttingen fertiggestellt werden. 


\section{Projektrelevante Vorträge und Publikationen}

- Vortrag: Körper in Flammen, Apparaturen im Wettstreit. Weltanschauung, Mentalität und politisches Bekenntnis in der Feuerbestattungstechnik des 19. Jahrhunderts. Mittwochsvortrag, DHI Rom 15. 3.

- Vortrag: Moderne und Asymmetrie: Ein deutsch-italienischer Vergleich. Incontro di studi Germania/Italia, lontane/vicine nazioni a confronto e orizzonti della modernità in occasione della pubblicazione del libro di Christof Dipper „Ferne Nachbarn“, Biblioteca di Ricerca di Area Umanistica, Neapel 25. 10.

- Zwischen Gesetz und Technik. Die Feuerbestattungsfrage des 19. Jahrhunderts als Prisma italienisch-jüdischer Selbstverortung, in: S. Böhmer/C. Breuer/T. MüllerBahlke/K. Tanner (Hg.), Technologien des Glaubens. Schubkräfte zwischen technologischen Entwicklungen und religiösen Diskursen. Acta Historica Leopoldina Nr. 71 (2017), S. 155-171.

Dr. Angela Steinsiek ( $a b$ 1. 11. 2017)

Ferdinand Gregorovius: Poesie und Wissenschaft. Gesammelte deutsche und italienische Briefe

\section{Allgemeine Projektbeschreibung}

Ferdinand Gregorovius ist neben Theodor Mommsen und Leopold von Ranke der bekannteste und heute vielleicht der am meisten gelesene deutsche Historiker des 19. Jahrhunderts. Neben seinem historiographischen und schriftstellerischen Euvre hat Gregorovius mehrere Tausend Briefe hinterlassen, die ein einzigartiges Dokument der europäischen Wissenschafts-, Zeit- und Kulturgeschichte darstellen. Ziel des Forschungsprojektes ist es, auf der Grundlage systematischer Recherche eine repräsentative Auswahl von 600 bis 700 deutschen und italienischen Briefen als kritische Ausgabe in Form einer Hybridedition (in einer Onlineversion und einer gedruckten Ausgabe) in den jeweiligen Originalsprachen zu erarbeiten und umfassend $\mathrm{zu}$ kommentieren. Innerhalb des Gesamtwerks von Gregorovius kommt dem umfangreichen Briefwechsel eine außerordentliche Bedeutung zu. Die Briefe sind nicht nur für das Verständnis des Werks von Gregorovius unentbehrlich, sondern sie beleuchten durch ihn als Zeitzeugen auch die italienische und die deutsche Geschichte des 19. Jahrhunderts. Das auf eine Laufzeit von vier Jahren angelegte Projekt wird seit 2017 von der Deutschen Forschungsgemeinschaft (DFG) gefördert.

\section{Arbeitsschwerpunkte im Berichtszeitraum}

In den ersten Wochen der Projektförderung wurde mit der Organisation des Teams und der Arbeit am deutschen Briefcorpus begonnen. 
PD Dr. Daniel Hedinger (ab 1. 9. 2017)

Imperien im Krieg. Der Zweite Weltkrieg aus transimperialer und (post)kolonialer Perspektive

\begin{abstract}
Allgemeine Projektbeschreibung
Der Zweite Weltkrieg war ein Kampf zwischen Imperien, ein Krieg um Imperien und um die Frage, welche imperiale Ordnung die Welt dominieren sollte. Doch sind wir daran gewöhnt, den Weltkrieg primär als einen Konflikt zwischen einzelnen Nationalstaaten zu verstehen. Das Projekt hinterfragt entgegen einer solchen Lesart erstens räumliche Dimensionen des Krieges und thematisiert die Globalität der jeweiligen Konstellationen. Dabei geht es darum zu zeigen, inwiefern und wie stark die einzelnen Hemisphären des Krieges verbunden waren, interagierten und wie sich dabei nationale und imperiale Fragen ergänzten und durchdrangen. Zweitens stellt die hier eingenommene Perspektive auch vertraute Periodisierungen in Frage. Wann und wo lassen wir den Zweiten Weltkrieg beginnen, wann, wie und wo enden? Für den kolonialen Raum scheint es naheliegend, nicht von einem eindeutigen Beginn und einem endgültigen Ende, sondern von mehreren Anfängen und Ausgängen zu sprechen. Drittens hat der bisherige Fokus auf nationalstaatliche Narrative eine Vielzahl von Akteuren marginalisiert. Daher zielt das Projekt auch darauf ab, Wahrnehmungsund Erwartungshorizonte einzelner Akteure, die in meist subalternen Positionen den Weltkrieg in erster Linie in kolonialen Kontexten durchlebten, zu rekonstruieren. Denn erst der systematische Einbezug von solchen „Geschichten von unten“ und Kriegserfahrungen aus außereuropäischen Kontexten macht die imperialen Dimensionen dieses Konflikts fassbar.
\end{abstract}

\title{
Arbeitsschwerpunkte im Berichtszeitraum
}

Einerseits lag der Fokus der Arbeit im Berichtszeitraum auf „globalem Faschismus“ und der Fertigstellung eines Manuskripts zur Geschichte der Achse Tokio - Rom Berlin. In diesem Kontext ist eine Reihe von Beiträgen, die voraussichtlich 2018 erscheinen sollen, entstanden, darunter: „The Spectacle of Global Fascism. The Italian Blackshirt Mission to Japan's Asian Empire“ (Modern Asian Studies, Cambridge University Press) sowie zusammen mit Moritz von Brescius, „The German and Japanese Empires. Great Power Competition and the World Wars“ (P. Bang/C. A. Bayly/W. Scheidel [Hg.], The Oxford World History of Empire, Oxford University Press). Im Anschluss an einen im September in Berlin organisierten Workshop mit dem Titel „In-Between Empires: Trans-Imperial History in a Global Age“ ging es andererseits darum, die Publikation der Ergebnisse vorzubereiten und gleichzeitig ein Netzwerk für transimperiale Geschichte zu schaffen. 


\section{Projektrelevante Vorträge und Veröffentlichungen}

- Vortrag: Beyond the master narrative? The Second World War in Trans-Imperial Perspective. Workshop „In-Between Empires: Trans-Imperial History in a Global Age“, Berlin 15.9.

- Podiumsdiskussion (mit H. Grandits, St. Kirmse und St. Rinke): „Wohlfahrt und Sicherheit“. Auftaktkonferenz „Diktaturen als alternative Ordnungen“ des interdisziplinären Verbunds für vergleichende Diktaturforschung an der HumboldtUniversität, Berlin 13. 10.

- Vortrag: Lost Legacies? The Axis, the Postcolonial and the Great Silence. Workshop „The Axis Powers and Decolonisation“, Berlin 14. 12.

- (mit R. Hofmann) (Hg.), Axis Empires. Toward a Global History of Fascist Imperialism, Cambridge: Cambridge University Press 2017 (Themenheft des Journal for Global History 12,2).

- The Imperial Nexus: The Second World War and the Axis in Global Perspective, in: ebd., S. 184-205.

- (mit R. Hofmann), Editorial - Axis Empires: Towards a Global History of Fascist Imperialism, in: ebd., S. 161-165.

Dr. Nicole Kramer (bis 30. 6. 2017)

Alter, Gebrechlichkeit und Pflege. Eine Gesellschaftsgeschichte wohlfahrtsstaatlicher Expansion in Westdeutschland, Großbritannien und Italien seit 1945

\section{Allgemeine Projektbeschreibung}

Die Studie untersucht die Entstehung und Entwicklung von Pflegepolitik in einem Vergleich und einer Beziehungsgeschichte zwischen der Bundesrepublik Deutschland, Großbritannien und Italien. Gefragt wird nach Prozessen der Perzeption und des Transfers, z. B. nach dem Einfluss zwischenstaatlicher Organisationen bei der Entwicklung von Lösungsansätzen oder der grenzübergreifenden Diskussion wissenschaftlicher Experten. Das Projekt richtet sich auf staatliche Interventionen in Form von Programmen und Regelungen, die pflegebedürftige alte Menschen selbst sowie das sie unterstützende Umfeld betreffen, und versteht sich als Beitrag zu einer Gesellschaftsgeschichte wohlfahrtsstaatlicher Expansion und einer Zeitgeschichte sozialer Vulnerabilität.

\section{Arbeitsschwerpunkte im Berichtszeitraum}

Der Forschungsaufenthalt in Rom wurde insbesondere zu Recherchen in Archiven und Bibliotheken genutzt, so in der Bibliothek des Istituto per gli Studi sui Servizi Sociali und der Parlamentsbibliothek, dem Archiv der Unione Donne Italiane, dem Gewerkschaftsarchiv der Associazioni Cristiane Lavoratori Italiani (ACLI) mit Sitz in Rom sowie in dem in Mailand beheimateten Archiv der Azienda di Servizi alla Persona „GOLGI-REDAELLI“, in dem die Überlieferung ihrer Vorgängereinrichtung, der Ente Comunale di Assistenza (ECA) di Milano, aufbewahrt ist. Ein großer Teil der Arbeits- 
zeit wurde darüber hinaus dafür verwendet, die bisherigen Ergebnisse in verschiedenen Vorträgen zu präsentieren. Die von der Gastwissenschaftlerin im Juni organisierte wissenschaftliche Exkursion gab Einblicke in die Arbeit der Unione Donne Italiane, der Casa Internazionale delle Donne und des Istituto Nazionale di Statistica. Diese Organisationen bzw. Institutionen bieten mit ihren Bibliotheken und Archiven nicht nur Wissensspeicher, sondern sind wichtige historische Akteure, beeinflussen aber auch noch heute die Gesellschaft und die Politik Italiens.

\title{
Projektrelevante Vorträge und Veröffentlichungen
}

- Vortrag: Von der Langlebigkeit zum vierten Alter. Pflegepolitik und die Expansion europäischer Wohlfahrtsstaaten nach dem Zweiten Weltkrieg. DHI Rom 15. 2.

- Vortrag: A Close Look at the History of the Italian Welfare State. Introduction. Tagung „The Making of the Italian Welfare Regime: National Specificities and European Entanglements“, DHI Rom 4. 5.

- Vortrag: La Germania nel secondo dopoguerra e il Welfare. Tagung „Capire la Germania“, Università degli Studi di Perugia 16. 5.

- Like a Solid Rock? Forces of Continuity and Silent Mutations within the Federal Republic of Germany's Welfare State Development, in: E. Eklund/ M. Oppenheimer/J. Scott (Hg.), The State of Welfare. Comparative Studies of the Welfare State and the End of the Long Boom 1965-1980, Oxford 2017, S. 151-175.

- Vers une coordination internationale de la politique du vieillissement: le Conseil de l'Europe et la République Fédérale d’Allemagne dans les années 60, in: Revue d'histoire de la protection sociale 10 (2017), S. 84-101.

- Der Wandel des italienischen Sozialstaats in Zeiten politischer Umbrüche, in: QFIAB 97 (2017), S. 3-23.

Dr. Amedeo Osti Guerrazzi (bis 30. 6. 2017)

Der Dienstkalender Benito Mussolinis

\begin{abstract}
Allgemeine Projektbeschreibung
Gegenstand des Projekts ist die Anlage einer Datenbank auf der Grundlage des teils im Archiv des italienischen Außenministeriums, teils im römischen zentralen Staatsarchiv überlieferten Dienstkalenders des faschistischen Diktators. Zwischen 1923 und 1945 hat Mussolini mehr als 90000 Audienzen gewährt, die in der Datenbank dokumentiert werden. Die Auswertung dieser Daten ermöglicht eine vertiefte Analyse der Herrschaftspraxis Mussolinis sowohl während der sog. Regimephase als auch während der Jahre der Repubblica Sociale Italiana. Die Datenbank gibt der internationalen Forschung ein wichtiges neues Instrument zur Untersuchung der Geschichte des Faschismus an die Hand.
\end{abstract}




\section{Arbeitsschwerpunkte im Berichtszeitraum}

Die Datenbank mit mehr als 93000 Einträgen wurde fertiggestellt und steht zur Nutzung im DHI zur Verfügung. Außerdem erwuchsen aus der Arbeit an der Datenbank zwei Manuskripte: „Mussolini in ufficio. La prassi di lavoro del dittatore fascista“ sowie „Le Udienze di Mussolini durante la Repubblica Sociale Italiana“.

\section{Projektrelevante Vorträge und Publikationen}

- Vortrag: Axis Wars. Internationale Tagung „Fascist Wars“, Konstanz 7.6.

- Vortrag: Italian Fascism at War. Internationale Tagung „Fascist Warfare. A Concept to Understand Fascism and Total War in the First Half of the Twentieth Century“, Barcelona 16. 3.

- Italians at War. War and War Experience in Fascist Italy, in: Journal of Modern Italian Studies, 12/2017, S. 589-605.

- La persecuzione degli ebrei a Roma. Carnefici e vittime, in: S. Haia Antonucci/ C. Procaccia (Hg.), Dopo il 16 ottobre. Gli ebrei a Roma tra occupazione, resistenza, accoglienza e delazioni (1943-1944), Roma 2017, S. 35-272.

- Antikommunismus im italienischen Faschismus, in: D. Rigoll/N. Frei (Hg.), Der Antikommunismus in seiner Epoche. Weltanschauung und Politik in Deutschland, Europa und den USA, Berlin 2017, S. 158-174.

- L'Historiographie de la Shoah en Italie. 1995-2015, in: Revue d'histoire de la Shoah (206), Mémorial de la Shoah, mars 2017, S. 25-45.

\section{Franziska Rohloff, M.A.}

Dorothea Wohlfarth, M.A. (ab 15. 7. 2017)

Geschichte der in Rom ansässigen deutschen Forschungs- und Kulturinstitute 1918-1962

\section{Projektbeschreibung}

Das vom Deutschen Archäologischen Institut, der Bibliotheca Hertziana - MPI für Kunstgeschichte sowie der Villa Massimo zusammen mit dem DHI getragene Projekt, das in Form zweier Dissertationsvorhaben durchgeführt wird, untersucht die Geschichte dieser deutschen Einrichtungen in Rom institutsübergreifend vor dem Hintergrund der politischen und gesellschaftlichen Umbrüche des Zeitalters der Weltkriege und des demokratischen Neuanfangs nach 1945. Im Mittelpunkt stehen Fragen des Verhältnisses von Wissenschaft, Kultur und Politik, der Beziehungen der deutschen Institutionen untereinander, ihrer Einbettung in die italienische und internationale Forschungslandschaft der Ewigen Stadt als einem Brennpunkt der Internationalisierung der Geisteswissenschaften, als exponiertem Ort des Austausches, der Konkurrenz und der politischen Vereinnahmung wissenschaftlicher Forschung.

\section{Arbeitsschwerpunkte im Berichtsjahr}

Die Vorarbeiten, die Franziska Rohloff im April 2016 auf Werkvertragsbasis begonnen hatte, endeten am 31. 3. 2017. Ab 1. 4. 2017 übernahmen die Projektfinanzierung 
das Auswärtige Amt und die Max Weber Stiftung. Innerhalb des Kooperationsprojekts werden neben zwei Dissertationen auch ein Digitalisierungsprojekt sowie eine - in Zusammenarbeit mit der Unione internazionale degli Istituti di archeologia, storia e storia dell'arte in Roma geplante - internationale Tagung finanziert, für die erste Vorbereitungen getroffen wurden. Ab 15. 7. 2017 fing Dorothea Wohlfarth als zweite Doktorandin an. Neben der Quellendokumentation in italienischen und deutschen Archiven wurden zwei und zugleich komplementäre Arbeitsgebiete mit je unabhängigen Quellenkorpora für die beiden Dissertationsvorhaben definiert.

\section{Projektrelevante Vorträge}

- Projektvorstellung: Besuch der Staatssekretärin des BMBF Cornelia QuennetThielen, DHI Rom 4. 10.

- Projektvorstellung: Wissenschaftliche Exkursion des Max-Planck-Instituts für europäische Rechtsgeschichte und gemeinsamer Workshop, DHI Rom 4. 10.

- Projektvorstellung: Abteilungsleiterkonferenz, Deutsches Archäologisches Institut Rom 7. 12.

\section{Musikwissenschaft}

\section{Dr. Richard Erkens}

Einflussgröße Impresario. Prämissen italienischer Opernaufführungen im 18. Jahrhundert

\section{Projektbeschreibung}

Das Forschungsprojekt konzentriert sich einerseits auf die Figur des Impresario und seinen Einfluss auf opernhistorische Entwicklungslinien, andererseits auf die sich wandelnde Operntopographie im vorrevolutionären Italien. Obwohl die Personengruppe der Impresari dieser Zeit heterogener nicht sein konnte, war die Tragweite ihrer Tätigkeit und damit ihr Einfluss auf die Opernaufführung in jeder der institutionellen Erscheinungsformen Hoftheater, Gesellschaftstheater und Impresariotheater von herausragender Bedeutung: Der Impresario war, so die Arbeitsthese, die maßgebliche Instanz für die Prämissen einer Aufführung und wurde zunehmend zur öffentlichen Figur in einer zwar regionalen, aber von überregionalen Entwicklungen abhängigen Theaterlandschaft. In dem Projekt sollen die Bedingungen, unter denen Impresari in verschiedenen Kontexten Entscheidungen trafen, rekonstruiert und deren tatsächliche Relevanz untersucht werden. Die Studie soll zur Klärung der Frage beitragen, inwieweit sich Produktionssystem und Topographie der italienischen Oper zwischen 1720 und 1780 veränderten bzw. konsolidierten und somit Voraussetzungen für die Etablierung der „Opernindustrie“ des 19. Jahrhunderts geschaffen werden konnten. 


\section{Arbeitsschwerpunkte im Berichtszeitraum}

Einen Schwerpunkt der Archivarbeiten zu römischen Impresari zwischen 1720 und 1740 bildete die Konsultation und Auswertung von Dokumenten zur Finanzierung von Theatern (Bilanzen, Kassenbücher, Rechnungsbücher - libri mastri - mit doppelter Buchführung usw.). Ein besonderes Augenmerk wurde dabei auf die Frage der Spielzeitfinanzierung der stagione di carnevale unterschiedlicher Bühnen für unterschiedliche Theatergattungen gelegt, um das Finanzvolumen von Produktionskosten und Einnahmen im Vergleich bestimmen zu können. Neben Dokumenten vorzugsweise aus den Zivilgerichtsakten des Archivio di Stato (Tribunale civile) wurden dafür auch die Materialien des Archivio Sovrano Militare dell'Ordine di Malta erschlossen (Rechnungsbücher des Teatro delle Dame, 1722-1737). Zur Erforschung der überregionalen Verflechtung von Impresari und des städteübergreifenden Produktionssystems von Opern stellt der Fondo Albizzi in Florenz (Archivio privato Guicciardini) umfassendes Briefmaterial bereit. Mit der Erschließung der Geschäftskorrespondenz des Florentiner Impresario Luca Casimiro degli Albizzi der Jahre 1722-1736 wurde begonnen; die handschriftlichen Quellen liefern überwiegend unerforschtes Grundlagenmaterial für Themen wie zeitliche und strategische Vertragsverhandlungen, Übernahme künstlerischer Kompetenzen, Handel von Partituren, Vermittlungstätigkeit, Künstlerbetreuung, Beeinflussung der Planungsarbeit durch politische Faktoren, überregionale persönliche Verflechtung (außerhalb der italienischen Halbinsel besonders London, Wien, St. Petersburg), Reflexionen über die eigene Tätigkeit als Impresario, Begleiten von Opernproduktionen in der Theaterperipherie (Livorno, Pisa, Pistoia) sowie der Vernetzung von Impresari untereinander.

\section{Projektrelevante Vorträge}

- Vortrag: Ruolo e influenza di un impresario a Roma: Giuseppe Polvini Faliconti (1717-1741). Colloquia 2017, Università degli Studi La Sapienza, Rom 8. 5.

- Vortrag: The Death of an Impresario (and What it Tells Us about Opera Production in the 1740s). Konferenz „tosc@bern.2017. 2nd transnational opera studies conference“, Universität Bern 5. 7.

- Stadtführung: Apollo an der Leine oder Die Oper in der Papststadt. Ein Rundgang zur wechselvollen Geschichte der öffentlichen Theater Roms. Studienkurs Rom des DHI, Rom 16. 9.

- Stadtführung: Opera riaperta: Römische Theater im frühen 18. Jahrhundert. Herbstführung des DHI Rom 17. 10.

\section{Dr. Chiara Pelliccia}

Topoi der Friedensdarstellung in der italienischen Kantate (17.-18. Jahrhundert)

\section{Projektbeschreibung}

Das Vorhaben bildet ein musikhistorisches Teilprojekt des interdisziplinären LeibnizProjekts „Dass Gerechtigkeit und Friede sich küssen - Repräsentationen des Frie- 
dens im vormodernen Europa“, unter der Ägide des Leibniz-Instituts für Europäische Geschichte in Mainz in Kooperation mit dem Germanischen Nationalmuseum Nürnberg, der Herzog August Bibliothek Wolfenbüttel, dem Historischen Institut der Polnischen Akademie der Wissenschaften Warschau und dem römischen DHI. Ein Ziel des Gesamtvorhabens ist die Erstellung eines in einer vom Germanischen Nationalmuseum betriebenen Datenbank erfassten Quellenkorpus, u. a. aus Literatur, Theologie, bildender Kunst und Musik, als Basis für weiterführende interdisziplinäre und vergleichende Forschungen zum Thema der Friedensdarstellungen in europäischer Perspektive. Neben der Grundlagenrecherche richten sich die Forschungen zur Kantate auf Typologien, Charakteristika und Funktionen musikalischer Friedensdarstellungen im Kontext von Friedensfeiern $u$. ä. sowie auf weitere kulturelle und politische Zusammenhänge. Dabei wird die Kantate im Verhältnis zu anderen zeitgenössischen Genres wie Serenata, Oper oder Oratorium untersucht, um ihre spezifischen Bedeutungen und Funktionen herauszuarbeiten.

\section{Arbeitsschwerpunkte im Berichtszeitraum}

Im Berichtsjahr konzentrierten sich die Arbeiten auf die Erfassung und Untersuchung von Kantaten im Kontext des Spanischen Erbfolgekriegs und damit verbundener Friedensfeiern. Zur Präsentation für eine virtuelle Ausstellung im Rahmen des Projekts wurden Kantaten aus dem Kontext der Friedensschlüsse von Hubertusburg und Paris gesammelt und aufbereitet. Weiterhin wurde der Gebrauch bestimmter Topoi sowie Personifizierungen des Friedens in Friedensfeiern in Serenaten, Oratorien und Opern und anderen Medien analysiert. Einen großen Teil der Arbeit beanspruchte die Erstellung der Friedensbilder-Datenbank (http://friedensbilder.gnm.de/).

\section{Projektrelevante Vorträge und Publikationen}

- Bericht über den aktuellen Stand des musikwissenschaftlichen Teilprojekts: Arbeitstreffen Friedensrepräsentationen, Wolfenbüttel 30.1.

- Projektvorstellung: Beiratssitzung, DHI Rom 4. 3.

- Vortrag: Riflessi della pace di Rijswijk sul mare di Anzio. Cantata e apparati per la visita di Innocenzo XII all'antico porto neroniano (1697). Studientag „Musica e pace. Nuove ricerche sull'età moderna“, DHI Rom 17. 5.

- Projektbericht: Studientag „Musica e pace. Nuove ricerche sull’Età moderna“, DHI Rom 18. 5.

- Vortrag: Politica, rivolte e violenza. Riflessi nel lamento per musica secentesco: Colloque international „La violence dans la révolte. Expériences politiques et pratiques culturelles“. École française de Rome, 12. 6.

- Bericht über den aktuellen Stand des musikwissenschaftlichen Teilprojekts: Arbeitstreffen Friedensrepräsentationen, Mainz 25. 9.

- Vortrag: Materiali e annotazioni per la mostra virtuale. Arbeitstreffen Friedensrepräsentationen, Mainz 6. 12. 


\section{Wissenschaftliche Datenverarbeitung}

Das Jahr 2017 stand im Zeichen der Abschlussarbeiten von Band X des Repertorium Germanicum (RG) zum Pontifikat Sixtus' IV. Dem Bereich der Digital Humanities des Instituts oblag hierbei die technische Koordinierung dieser Arbeiten. Für das sechsköpfige, über verschiedene Standorte verteilte Team unter Leitung von Jörg Voigt wurde eine Arbeitsumgebung geschaffen, die es ermöglichte, kollaborativ den gesamten Datenbestand so zu bearbeiten, dass am Ende ein homogener Text als Grundlage für die Registererstellung vorlag. Parallel dazu wurde mit Hilfe eines Dienstleisters im Bereich automatisierter Werksatz mit der automatischen Erstellung der umfangreichen Register begonnen. Die Druckvorlage des Bandes, die zugleich Grundlage der Online-Version ist, wird in enger Abstimmung mit dieser Firma hergestellt. Erste Auswertungen des neuen Datenbestandes konnten den Beiratsmitgliedern auf ihrer Jahressitzung im März präsentiert werden. Neben den sich über das ganze Jahr erstreckenden Arbeiten an der Drucklegung wurde einem ausgewählten Kreis von Wissenschaftlern/-innen der Zugang zu den Daten schon vorab über ein Webinterface ermöglicht, das zugleich die Grundlage für eine überarbeitete Version des RG Online bildet. Innerhalb eines größeren Relaunches soll es den Nutzern einen intuitiveren und funktionsreicheren Zugriff auf den gesamten Datenbestand des RG ermöglichen. Aus den Vorarbeiten zur automatisierten Registererstellung hat sich im Laufe des Jahres ein eigenes Teilprojekt entwickelt. Darin soll versucht werden, mit graphbasierten Ansätzen den Blick weg von der reinen Auflistung von Personen und Institutionen hin auf deren Beziehungen untereinander zu richten. Zentrale Fragestellungen bezüglich der Netzwerkstrukturen dieser Akteure lassen sich mit den herkömmlichen technischen Mitteln nur unzureichend bzw. nicht beantworten. Mittels graphbasierter Analysemöglichkeiten soll das im RG und Repertorium Poenitentiariae Germanicum (RPG) verfügbare gewaltige serielle Quellenmaterial - allein im Band X des RG werden über 60000 relevante Quellen aufbereitet - in Zukunft mit neuen Fragestellungen und Methoden ausgewertet werden.

In dem in Kooperation von Lutz Klinkhammer und Amedeo Osti Guerrazzi durchgeführten Projekt zum Dienstkalender Mussolinis (1923-1945) wurde nach Abschluss der Erstellung der Datenbank mit der Vereinheitlichung des Namenregisters begonnen. Hierzu müssen in einem ersten Schritt die zahlreichen erfassten Personen und Institutionen mit semiautomatischen Verfahren zusammengefasst werden. Eine manuelle Kontrolle bleibt jedoch in vielen Fällen unerlässlich. Eine erste Betaversion der Digitalen Edition des Briefwechsels zwischen König Ludwig I. von Bayern und Johann Martin von Wagner konnte mit Hilfe von Jens Röschlein innerhalb eines Projektpraktikums entwickelt werden. Das Projekt wird in Kooperation mit der Kommission für bayerische Landesgeschichte bei der Bayerischen Akademie der Wissenschaften durchgeführt. Die Onlineveröffentlichung ist für 2018 geplant.

Über den erfolgreichen Antrag des Projektes „Ferdinand Gregorovius: Poesie und Wissenschaft. Gesammelte deutsche und italienische Briefe“ bei der DFG konnten für 
die nächsten drei Jahre Mittel für eine halbe Wissenschaftlerstelle im Bereich der DH eingeworben werden, über die zudem eine Kooperation mit der Berlin Brandenburgischen Akademie der Wissenschaften im Bereich der DH initiiert wird. Hauptaufgabe wird die Entwicklung eines digitalen Publikationskonzepts sowie die Implementierung der Webapplikation auf Basis von DENQ sein. Das Engagement der römischen Digital Humanities im AK DH der Max Weber Stiftung schlug sich in der institutsübergreifenden Ausarbeitung des detaillierten Grundlagenpapiers „Konzept des Arbeitskreises Digital Humanities - Bestandsaufnahme und Empfehlungen zu den Digital Humanities in der Max Weber Stiftung“ nieder.

\section{Veranstaltungen}

\section{Wissenschaftliche Tagungen und Workshops}

23. -24.1 .

Dritter Workshop des Forschungsprojektes „Spaces of Expectation“: Semantics of Space: Conceptual History Perspectives

in Zusammenarbeit mit der Södertörn Universität Stockholm und der Università Ca' Foscari Venedig.

22.-24. 2.

Internationale Tagung: Luther in Italy

in Zusammenarbeit mit der Biblioteca Casanatense, dem Ministero dei beni e delle attività culturali e del turismo, mit Unterstützung der Society for the History of Authorship, Reading \& Publishing.

\section{2.}

Studientag: Leibniz, Jablonski und Berlin

in Zusammenarbeit mit dem Istituto per il Lessico Intellettuale Europeo e Storie delle Idee und dem Consiglio Nazionale delle Ricerche di Roma, dem Progetto LCA, dem Deutschen Kulturforum Östliches Europa, der Daniel Ernst Jablonski-Forschungsstelle an der Universität Stuttgart, der Berlin-Brandenburgischen Akademie der Wissenschaften, unter der Schirmherrschaft der Sodalitas Leibnitiana.

16. -17.3.

Interner Workshop: Perspektiven für die Endredaktion des Repertorium Germanicum (Bd. X: Sixtus IV.). 
21. 3.

Internationaler Studientag und Fortbildungsseminar für Dozenten und Professoren: Prigionieri del lavoro. Lo sfruttamento del lavoro forzato in Italia e in Europa 19391945

organisiert vom Istituto Romano per la storia d'Italia dal fascismo alla resistenza in Zusammenarbeit mit Topografia per la Storia, EVZ Berlin, ZVOD APIS Ljubljana und dem DHI Rom (Casa della Memoria e della Storia, Rom).

22.-24. 3.

Internationale Tagung: Menschenrechte in der katholischen Kirche. Historische, systematische und praktische Perspektiven

organisiert vom Netzwerk menschenrechtsbezogener theologischer Forschung in Zusammenarbeit mit dem Institut für Christliche Sozialwissenschaften (WWU Münster), Institut für Katholische Theologie (Universität Köln), Institut für Katholische Theologie (Universität Wuppertal) und dem DHI Rom.

31. 3.

Interdisziplinärer Studientag: Qual è la funzione del ricordo dei crimini nazisti? Storici e psichiatri si confrontano sui processi della memoria riguardanti la persecuzione dei malati mentali e dei disabili durante il nazionalsocialismo e la loro condizione nel fascismo

organisiert vom DHI Rom und Netforpp Europa, in Zusammenarbeit mit der Società Italiana di Storia della Psichiatria (sezione della Società Italiana di Psichiatria), der Agenzia per la Vita Indipendente onlus Roma, dem Museo Laboratorio della Mente Roma e ASL Roma1, dem Istituto per la storia del pensiero filosofico e scientifico moderno - CNR; unter der Schirmherrschaft der Botschaft der Bundesrepublik Deutschland Rom und der italienischen Abgeordnetenkammer.

10. -13.4 .

Internationale Tagung der interdisziplinären DFG-Forschergruppe „Urbane Ethiken“ (angesiedelt an den Universitäten München, Göttingen und Regensburg): Ethische Debatten und urbane Praxen

in Zusammenarbeit mit dem DHI Rom.

27. 4.

Studientag: Alleati contro il Bolscevismo. La guerra in Russia della divisione „Azul“ e dell'ARMIR, 1941-1944. Storia e memoria.

4. -5.5 .

Internationale Tagung: The Making of the Italian Welfare State: National Specifities and European Entanglements. 
16. -17.5 .

Internationale Tagung: Capire la Germania

organisiert vom Dipartimento di Scienze Politiche der Universität Perugia in Zusammenarbeit mit dem DHI Rom (Universitá di Perugia).

\section{5 .}

Workshop: Musica e pace. Nuove ricerche sull'età moderna

im Rahmen des internationalen Verbundprojekts „,Dass Gerechtigkeit und Friede sich küssen'. Repräsentationen des Friedens im vormodernen Europa“ mit einem Konzert des Ensemble Chordis mit Friedenskompositionen des 15.-18. Jahrhunderts.

30. 5. -1. 6 .

Workshop: Going Native or Remaining Foreign? Catholic Missionaries as Local Agents in Asia (17th to 18th Centuries)

organisiert vom DHI Rom, der École française de Rome, dem Istituto Svizzero di Roma und der Abteilung für Neuere Geschichte des Historischen Instituts der Universität Bern.

15.-17. 6 .

19. Tagung der Arbeitsgemeinschaft für die Neueste Geschichte Italiens: Krieg und Frieden in der Neuesten Geschichte Italiens

in Zusammenarbeit mit dem DHI Rom (Stiftung Demokratie Saarland, Saarbrücken).

20. 6.

Podiumsdiskussion: Einfache Antworten auf schwierige Fragen? Populismus heute und gestern

im Rahmen der Veranstaltungsreihe der Max Weber Stiftung „Geisteswissenschaft im Dialog“ gemeinsam mit der Union der deutschen Akademien der Wissenschaften und dem DHI Rom (Berlin-Brandenburgische Akademie der Wissenschaften, Berlin).

22.-23. 6.

Internationaler Workshop: Gender - Nation - Emancipation. Women and Families in the „long“ Nineteenth Century in Italy and Germany

organisiert vom DFG-Netzwerk „Gender - Nation - Emancipation“ in Zusammenarbeit mit dem DHI Rom und der Wissenschaftlichen Arbeitsgemeinschaft des Leo Baeck Instituts in der Bundesrepublik Deutschland.

29. 6 .

Workshop: From the Spanish Civil War to World War II. Trajectories of Transnational Antifascist Volunteers

organisiert von der University of Leeds in Zusammenarbeit mit dem DHI Rom (School of History, Leeds). 


\section{7.}

Othering in Pre-Norman Southern Italy. International Medieval Congress Leeds

Drei Sektionen der Tagung in Leeds wurden organisiert vom Institut für Mittelalterforschung der Österreichischen Akademie der Wissenschaften in Wien und dem DHI in Rom:

I: Perceptions and Contexts

II: Otherness in Culturally Divergent Societies

III: Non-Christians and Non-Muslim as a Challenge.

21.-23. 9.

Stiftungskonferenz der Max Weber Stiftung: Revolutionäre Biographien im 19. und 20. Jahrhundert. Imperial - international - dekolonial organisiert mit Beteiligung des DHI Rom (DHI Moskau).

9. -10.11 .

Internationale Tagung der Willibald-Pirckheimer-Gesellschaft: Ulrich von Hutten und Rom. Deutsche Humanisten in der Ewigen Stadt am Vorabend der Reformation in Zusammenarbeit mit dem DHI Rom.

15. -17.11 .

Interdisziplinäre internationale Tagung: Making Truth-Administrating Truth. Establishing Credibility in Early Modern History

organisiert vom DHI Rom, der Goethe-Universität Frankfurt am Main und der Universität Gent in Zusammenarbeit mit der Academia Belgica Roma, mit finanzieller Unterstützung der Deutschen Forschungsgemeinschaft (DFG) und des Fonds Wetenschappelijk Onderzoek.

\section{Sonstige Veranstaltungen}

30. 1.-3. 2.

Winter School: Die Levante als Kontaktraum zwischen Europa und dem Orient des Historischen Instituts der Universität des Saarlandes, geleitet von Prof. Dr. Heinrich Schlange-Schöningen (Universität des Saarlandes), Prof. Dr. Peter Thorau (Universität des Saarlandes) und Dr. Kordula Wolf (DHI Rom).

13.-18. 2.

Winter School: „Katholizismus und Moderne“ - Zur Kulturbedeutung ihres Verhältnisses im Vergleich zwischen Deutschland und Italien

der Ludwig-Maximilians-Universität München und des Max Weber-Programms Bayern, in Kooperation mit dem DHI Rom, geleitet von Prof. Dr. Dr. Elisabeth Zwick (Ludwig-Maximilians-Universität München). 
9. 3.

Arnold Esch, Rom. Vom Mittelalter zur Renaissance (C. H. Beck 2016). Buchpräsentation mit Christoph Frommel (Dir. em. Bibliotheca Hertziana), Massimo Miglio (Istituto Storico Italiano per il Medioevo), Anna Modigliani (RR Roma nel Rinascimento), JeanClaude Maire Vigueur (Università degli Studi Roma Tre).

\section{3.}

Geschichte, Fiktion, Imagination. Martin Baumeister im Gespräch mit Christoph Poschenrieder über dessen Roman „Das Sandkorn“

organisiert von der Max Weber Stiftung in Zusammenarbeit mit dem DHI Rom (Historisches Kolleg, München).

3. -9.4.

Studienkurs: Rom als Palimpsest

organisiert von der Bibliotheca Hertziana - Max-Planck-Institut für Kunstgeschichte, dem Deutschen Archäologischen Institut und dem DHI Rom.

4.-8. 9 .

Summer School: Regesta Imperii

der Friedrich-Alexander-Universität Erlangen-Nürnberg, geleitet von Prof. Dr. Klaus Herbers, in Zusammenarbeit mit dem DHI Rom.

10.-19. 9 .

Romkurs 2017

Studienkurs des DHI Rom für fortgeschrittene Studenten und Doktoranden des Faches Geschichte.

21. 9.

Concentus musicus XVI: Niccolò Piccinni, La buona figliuola. Kritische Ausgabe hg. von Francesco Paolo Russo, Kassel 2017. Buchpräsentation mit Lorenzo Bianconi (Università degli Studi di Bologna).

11. 12 .

Rudolf Schlögl, Fede e mondo moderno. La trasformazione del Cristianesimo europeo tra 1750 e 1850, edizione italiana a cura di Marco Cavarzere, traduzione a cura di Elvira Lima (New Digital Frontiers 2017). Buchpräsentation mit Fabrice Jesné (École française de Rome) und Vincenzo Lavenia (Università degli Studi di Macerata). 
14. 12.

Martin Baumeister/Bruno Bonomo/Dieter Schott (Hg.), Cities Contested. Urban Politics, Heritage, and Social Movements in Italy and West Germany in the 1970s (Campus 2017). Buchpräsentation mit Lidia Piccioni (Università degli Studi La Sapienza Rom), Salvatore Adorno (Università degli Studi di Catania) und Stefano Cavazza (Università degli Studi di Bologna) (Biblioteca di Storia Moderna e Contemporanea, Rom).

\section{Vortragsveranstaltungen}

23. 1. Diana Mish kova (Centre for Advanced Study Sofia)

Conceptualization of Historical Regions and Boundaries

Abendvortrag im Rahmen der Tagung „Semantics of Space: Conceptual History Perspectives“

22. 2. Paul F. Grendler (University of Toronto)

After Luther: Freedom and Censorship in Medicine and Education

Abendvortrag im Rahmen der Tagung „Luther in Italy“

3. 3. Irmgard Fees (Ludwig-Maximilians-Universität München)

Aurea Roma. Siegelwesen und Rompolitik Friedrich Barbarossas

Jahresvortrag anlässlich der Sitzung des Wissenschaftlichen Beirats

20. 3. Joachim Bahlcke (Universität Stuttgart)

Zwischen arcanum und publicum. Das Interesse an der Korrespondenz Daniel Ernst Jablonskis vom 17. Jahrhundert bis zur Gegenwart

Vortrag zum Abschluss der Ausstellung „Brückenschläge - Daniel Ernst Jablonski im Europa der Frühaufklärung“

22. 3. Daniele Menozzi (Scuola Normale Superiore Pisa)

La Chiesa cattolica e i diritti umani. Contraddizioni, convergenze ed ambivalenze in una prospettiva storica

Abendvortrag im Rahmen der Tagung „Menschenrechte in der katholischen Kirche. Historische, systematische und praktische Perspektiven“

23. 3. Heiner Bielefeldt (Friedrich-Alexander-Universität Erlangen-Nürnberg)

Zwischen Nähe und Fremdheit. Rezeption der Menschenrechtsidee seitens der Religionsgemeinschaften am Beispiel der katholischen Kirche

Abendvortrag im Rahmen der Tagung „Menschenrechte in der katholischen Kirche. Historische, systematische und praktische Perspektiven“ (Deutsche Botschaft beim Heiligen Stuhl, Rom) 
11. 4. Christoph Neumann (Ludwig-Maximilians-Universität München)

Demolishing Buildings, Creating Monuments: The Urban Heritage of Istanbul between the Constructing of Identities and the Negotiating of Ethics, Late Ottoman to Late Kemalist Times

Abendvortrag im Rahmen der Tagung „Ethische Debatten und urbane Praxen“

\section{5. Christoph Cornelißen (Goethe-Universität Frankfurt am Main)}

Il Welfare State in Europa e dell'Europa: visioni e realtà dal 1945

Abendvortrag im Rahmen der Tagung „The Making of the Italian Welfare State: National Specifities and European Entanglements“

\section{6. Axel Körner (UCL Centre for Transnational History)}

Gender, War and Nation Building: Nineteenth-Century Italy in a Trans-Atlantic Context Abendvortrag im Rahmen des Workshops „Gender - Nation - Emancipation. Women and Families in the ,long ' Nineteenth Century in Italy and Germany“

25. 6. Il giallo e il fascismo. Gespräch zwischen Harald Gilbers und Maurizio de Giovanni, moderiert von Angelo Bolaffi

Im Rahmen des „KRIMI - Festival dedicato al giallo tedesco contemporaneo“, organisiert von emons: libri \& audiolibri, mit Unterstützung des DHI Rom (Cinema Nuovo Sacher, Rom)

6. 10. Sible de Blaauw (Radboud-Universiteit Nijmegen)

Johannes vor der Lateinischen Pforte. Eine römische Kirche und der Apostelkult zwischen Byzanz und Rom

Vortrag im Rahmen der Jahressitzung des Vereins der Freunde des DHI Rom e. V.

11. 10. Claudio Monteverdis 450. Geburtstag

Silke Leopold (Universität Heidelberg)

„Sopra li fondamenti della verità“. Claudio Monteverdi e la musica moderna Aaron Carpenè (Rom) und Stefano Vizioli (Rom/Pisa)

Projektpräsentation „Japan Orfeo“ (Kamakura und Tokyo 2016). Ein Projekt der „Cultural Diplomacy“: die Inszenierung von Monteverdis Meisterwerk „Orfeo“ (1607) im Zusammenspiel von italienischer Lichttechnik, Mode und Choreographie und Japans traditionellem Theater (Nō), Tanz (Nihon Buyō) und Musik (Gagaku)

\section{Musicologia oggi, Vortragszyklus „Klangbild Reformation“}

30. 3. Irmgard Scheitler (Würzburg)

Lutherus redivivus. Zur Musikgeschichte frühneuzeitlicher Reformationsjubiläen 
11. 5. Siegfried Matthus (Berlin)

Herausforderung Reformationsjahr. Zur Dramaturgie meiner musikalischen Vision ,Luthers Träume‘ (2017)

26. 10. Thomas Schmidt (University of Manchester)

Failed, Rejected, Misunderstood? On the Misplaced Nature of Mendelssohn's ,Reformation'Symphony

7. 12. Ralf Hoyer (Berlin)

,Wachet recht auff': Ralf Hoyer (Berlin) über sein Oratorium zum Luther-Jahr 2017 (Werkstattbericht mit Videoausschnitten)

\section{Kinolektionen}

5. 4. Condottieri (I/D 1937)

Regie: Luis Trenker

Einführung: Heinrich Lang (DHI Rom)

7. 11. My Cousin - Caruso (USA 1918)

Regie: Edward José

Einführung: Richard Erkens (DHI Rom)

\section{Rome Modern Italy Seminar}

4. 4. Patrick Houlihan (Universität Oxford)

Global Catholicism during the First World War

\section{Mittwochsvorträge}

11. 1. Amedeo Osti Guerrazzi

La cooperazione italo-tedesca nella deportazione degli ebrei dall'Italia

15. 2. Nicole Kramer

Von der Langlebigkeit zum vierten Alter. Pflegepolitik und die Expansion europäischer Wohlfahrtsstaaten nach dem Zweiten Weltkrieg

\section{3. Carolin Kosuch}

Körper in Flammen, Apparaturen im Wettstreit. Weltanschauung, Mentalität und politisches Bekenntnis in der Feuerbestattungstechnik des 19. Jahrhunderts 
26. 4. Heinrich Lang

Frühneuzeitliche Staatsbankrotte. Akteurszentrierte Analyse der europäischen Kreditmärkte um 1550

24. 5. Chiara Petrolini

Roma, Vienna e l'Oriente all'inizio del '600: le lettere di Sebastian Tengnagel e Pietro Della Valle

26. 6. Anna Grillini

Il prezzo della fuga dalla guerra. L'autolesionismo nelle carte dell'Archivio dell'Ufficio Storico dello Stato Maggiore dell'Esercito

6. 9. Jörg Voigt

Neue Aspekte der Kuriengeschichte im Spätmittelalter. Zu den Auswertungsmöglichkeiten des RG und RPG

25. 10. Marie Bossaert

Un capitale linguistico. Percorsi e appartenenza dei figli d'immigrati italiani a Costantinopoli

28. 11. John Davis

Two Contemporary Lost Causes: The American Confederacy and Italy's Southern Question

13. 12. Matteo Stefanori

Ebrei stranieri a Roma (1933-1944)

\section{Herbstführungen}

17. 10. Richard Erkens

Opera riaperta: Römische Theater im frühen 18. Jahrhundert. Eine Stadtführung zu vergessenen und zerstörten Opernbühnen

28. 10. Carolin Kosuch

Der nicht-katholische Friedhof in Rom

11. 11. Kordula Wolf

Il borgo medievale di Ostia e il castello di Giulio II

25. 11. Jörg Voigt

Der Lateran im Mittelalter

QFIAB 98 (2018) 


\section{Publikationen}

\section{Institut}

2017 sind erschienen:

Quellen und Forschungen aus italienischen Archiven und Bibliotheken, Bd. 96, Berlin-Boston 2017, LXX u. $711 \mathrm{~S}$.

Bibliothek des Deutschen Historischen Instituts in Rom:

Bd. 132: Andreas Rehberg (Hg.), Ablasskampagnen des Spätmittelalters. Luthers Thesen von 1517 im Kontext, Berlin-Boston 2017, XVII u. 712 S.

Bd. 133: Silvano Longhi, Exil und Identität. Die italienischen Juden in der Schweiz (1943-1945), Berlin-Boston 2017, X u. 530 S.

Bd. 134: Michael Matheus/Arnold Nesselrath/Martin Wallraff (Hg.), Martin Luther in Rom. Die Ewige Stadt als kosmopolitisches Zentrum und ihre Wahrnehmung, Berlin-Boston 2017, XVII u. 534 S.

Ricerche dell'Istituto Storico Germanico di Roma:

Bd. 11: Patrick Bernhard/Lutz Klinkhammer (Hg.), L'uomo nuovo del fascismo. La costruzione di un progetto totalitario, Roma 2017, 290 S.

Analecta musicologica:

Bd. 51: Giancarlo Rostirolla, La Cappella Giulia 1513-2013. Cinque secoli di musica sacra in San Pietro, 2 Bde., Kassel u. a. 2017, 772 u. 792 S.

Concentus musicus:

Bd. XVI: Niccolò Piccinni, La buona figliuola, kritische Ausgabe hg. von Francesco Paolo Russo, Kassel u.a. 2017, XIX u. 506 S.

Online-Schriften des DHI Rom. Neue Reihe / Pubblicazioni online del DHI Roma. Nuova serie:

Bd. 1: Wolfgang Reinhard, Kleinere Schriften zur Rom-Forschung. Wolfgang Reinhard zum 80. Geburtstag am 10. April 2017, hg. für die „Italien-AG“ von Birgit Emich in Zusammenarbeit mit Arne Karsten, Hillard von Thiessen und Günther Wassilowsky, Rom 2017, URL: http://www.dhi-roma.it/reinhard-kleinere-schriften.html.

Perspectivia.net:

QFIAB 95 (2015) (URL: http://www.perspectivia.net/publikationen/qfiab/95-2015). 
Recensio.net:

Alle Rezensionen des QFIAB-Bandes 95 (2015) wurden auf recensio.net online gestellt (URL: http://www.recensio.net/rezensionen/zeitschriften/quellen-und-forschungenaus-italienischen-archiven-und-bibliotheken/index_html).

Bibliographische Informationen zur neuesten Geschichte Italiens. Informazioni bibliografiche sulla storia contemporanea italiana, Hefte Nr. 152 (November 2016) - 154 (Juli 2017) (URL: http://dhi-roma.it/bibl_inf.html).

Im Druck:

Quellen und Forschungen aus italienischen Archiven und Bibliotheken 97 (2017).

Repertorium Poenitentiariae Germanicum:

Bd. 11: Hadrian VI. 1522-1523. Text und Indices bearb. von Ludwig Schmugge, Berlin-Boston 2018, XXX, 306 S.

Analecta musicologica:

Bd. 54: Peter Nied ermüller (Hg.), Klangkultur und musikalische Interpretation. Italienische Dirigenten im 20. Jahrhundert.

In Vorbereitung:

Bibliothek des Deutschen Historischen Instituts in Rom:

Bd. 135: Moritz Buchner, Warum weinen? Die Trauerkultur der italienischen Eliten, 1850-1915.

Bd. 136: Guido Braun (Hg.), Diplomatische Wissenskulturen der Frühen Neuzeit. Erfahrungsräume und Orte der Wissensproduktion.

Analecta musicologica:

Bd. 55: Sabine Ehrmann-Herfort (Hg.), Alessandro Scarlatti.

Bd. 56: Roberto Scoccimarro, Die Drammi seri von Leonardo Leo (1694-1744). Studien zur Überlieferung, Stilistik, Rezeption.

Concentus musicus:

Bd. XVII: Giuseppina Mascari (Hg.), Giovanni Pacini, Gli Arabi nelle Gallie.

Repertorium Germanicum:

Bd. 10: Sixtus IV. (1471-1484), bearb. von Ulrich Schwar z/Juliane Trede/Stefan Brüdermann/Thomas Bardelle/Kerstin Rahn/Hubert Höing/Michael Reimann/ Sven Mahmens. 
Nuntiaturberichte aus Deutschland nebst ergänzenden Aktenstücken:

III. Abteilung: 1572-1585, Bd. 11: Nuntiaturen des Giovanni Francesco Bonomi und des Germanico Malaspina (1581-1585), bearb. von Alexander Koller.

Hauptinstruktionen (Instructiones Pontificum Romanorum):

Le istruzioni generali di Urbano VIII ai diplomatici pontifici 1623-1644, a cura di Silvano Giordano OCD.

Online-Schriften des DHI Rom. Neue Reihe / Pubblicazioni online del DHI Roma. Nuova serie:

Silvia Di Paolo, Amor in libris imprimendis. L'itinerario del canonista Giovanni Francesco Pavini all'origine della modernità giuridica.

Amedeo Osti Guerrazzi, Le Udienze di Mussolini durante la Repubblica Sociale Italiana.

Laura Pettinaroli/Massimiliano Valente (Hg.), Pietro Gasparri segretario di Stato (1914-1929).

\section{Institutsmitarbeiter/-innen}

Martin Baumeister

- mit B. Bonomo und D. Schott (Hg.), Cities Contested. Urban Politics, Heritage and Social Movements in Italy and West Germany in the 1970s, Frankfurt am Main/ New York 2017.

- mit B. Bonomo und D. Schott, Introduction. Contested Cities in an Era of Crisis, in: ebd., S. 7-30.

- mit H. Glaser und H. Putz (Hg.), bearbeitet von M. R. Hofter und J. Selch, in Zusammenarbeit mit F. Freitag und J. Zedler, König Ludwig I. von Bayern und Johann Martin von Wagner. Der Briefwechsel, Band I/1: 1809-1811 und Band I/2: 1812-1815, München 2017 (Quellen zur Neueren Geschichte Bayerns V).

Sabine Ehrmann-Herfort

- „Gewürz, Honig und süßester Zucker für unsere Ohren und Augen“. Rhetorik und Musik im italienischen Musikschrifttum der Frühen Neuzeit, in: Rhetorik 35 (2016), S. 57-72.

- „Dass Gerechtigkeit und Friede sich küssen“ - Repräsentationen des Friedens im vormodernen Europa. Ein interdisziplinäres Verbundprojekt, in: QFIAB 96 (2016), S. 470-487.

- Von Anfang an in besonderen Rollen: Zur Begriffsgeschichte von ,tenor ‘ bis ins 17. Jahrhundert, in: Der Tenor. Mythos - Geschichte - Gegenwart, hg. von C. Herr, A. Jacobshagen und Th. Seedorf (Musik - Kultur - Geschichte 8), Würzburg 2017, S. 81-104. 
- Der russische Hof entdeckt die italienische Oper - ein Prestigeobjekt, in: Musik am russischen Hof. Vor, während und nach Peter dem Großen (1650-1750), hg. von L. Erren, Berlin und Boston 2017 (Veröffentlichungen des Deutschen Historischen Instituts Moskau 7), S. 119-136.

- Römische Musikorte. Zur musikalischen Topographie Roms um 1700, in: Göttinger Händel-Beiträge 18 (2017), hg. von L. Lütteken und W. Sandberger, S. 33-56.

- Zur Migration musikalischer Begriffe im Europa der Frühen Neuzeit, in: Forum Interdisziplinäre Begriffsgeschichte (FIB), E-Journal, hg. von E. Müller, 6/1 (2017), S. 67-76, online: http://www.zfl-berlin.org/tl_files/zfl/downloads/publikationen/forum_begriffsgeschichte/ZfL_FIB_6_2017_1.pdf.

\section{Markus Engelhardt}

- mit Ch. Husch (Hg.), Athanasius Kircher, Musurgia universalis (Rom 1650), deutsche Übersetzung von G. Scheibel, http://www.hmt-leipzig.de/de/home/fachrichtungen/institut-fuer-musikwissenschaft/forschung/musurgia-universalis.

- Literatur und Musik - eine Miszelle, in: R. J. Kaus/H. Günther (Hg.), Was ist Literatur?/What is Literature, Berlin 2017, S. 251-265.

- „Teatro è Roma e il Campidoglio è scena“. Roma come metafora del mondo nella librettistica barocca, in: G. Rostirolla/E. Zomparelli (Hg.), Tra musica e storia. Saggi di varia umanità in ricordo di Saverio Franchi, Roma 2017, S. 469-481.

- Premessa, in: P. Maurizi/P. Fanny/W. Hensel (Hg.), Un contributo critico, Lucca 2017 (Studi e Saggi 6), S. VVII-VIII.

\section{Richard Erkens}

- (Hg.), Puccini-Handbuch, Stuttgart-Kassel 2017.

- Konstante Aneignung: Puccini und die Opernlandschaft seiner Zeit, in: ebd., S. 54-66.

- Komponierte Regie: Prinzipien der formalen Disposition, in: ebd., S. 124-137.

- Puccinis Imagination von szenischem Raum: Bühnenbild, Licht, Kostüm und Bewegung, in: ebd., S. 170-182.

- „voler far piangere“ - Aspekte einer Opernästhetik Puccinis, in: ebd., S. 195-204.

- Werkartikel zu Le Villi, Edgar, Manon Lescaut, Tosca, Madama Butterfly (mit R. Pecci) und Turandot, in: ebd., S. 206-211; 212-219; 220-231; 242-251; 251-264, 309-322.

- Sinfonismo und Wagnerismo. Imitationen der Musiksprache Wagners in Italien, in: A. Stollberg/I. Rentsch/A. Gerhard (Hg.), Gefühlskraftwerke für Patrioten? Wagner und das Musiktheater zwischen Nationalismus und Globalisierung, Würzburg 2017, S. 431-473.

Daniel Hedinger

- The Spectacle of Global Fascism. The Italian Blackshirt Mission to Japan's Asian Empire, in: Modern Asian Studies 51,6 (2017), S. 1999-2034. 
- mit R. Hofmann (Hg.), Axis Empires. Toward a Global History of Fascist Imperialism. Themenheft des Journal for Global History 12,2 (2017).

- mit R. Hofmann, Editorial - Axis empires: Towards a Global History of Fascist Imperialism, in: ebd., S. 161-165.

- The Imperial Nexus: The Second World War and the Axis in Global Perspective, in: ebd., S. 184-205.

Jörg Hörnschemeyer

- Textgenetische Prozesse in Digitalen Editionen. Dissertation, Universität zu Köln 2017, http://kups.ub.uni-koeln.de/id/eprint/7544.

Lutz Klinkhammer

- mit P. Bernhard (Hg.), L'uomo nuovo del fascismo. La costruzione di un progetto totalitario, Roma 2017 (Ricerche dell'Istituto Storico Germanico di Roma 11).

- mit P. Bernhard, L',uomo nuovo“ del fascismo. Tra progetto e azione, in: ebd., S. 9-27.

- Der „Schrank der Schande“ und das „Vergessen“ eines Bürgerkriegs. Der Untersuchungsausschuss des italienischen Parlaments zur Aufdeckung der Nichtverfolgung von nationalsozialistisch-faschistischen Gewaltverbrechen, in: Ch. Cornelißen/P. Pezzino (Hg.), Historikerkommissionen und historische Konfliktbewältigung, Übersetzung der italienischen Beiträge von G. Kuck, BerlinBoston 2018 [ausgeliefert 2017], S. 153-176.

Alexander Koller

- mit R. González Cuerva (Hg.), A Europe of Courts, a Europe of Factions. Political Groups at Early Modern Centres of Power (1550-1700), Leiden 2017.

Carolin Kosuch

- Anarchisches Heil? Fritz Brupbachers Sozialdiagnosen zwischen Psychiatrie, Sozialismus und Literatur, in: L. Greisiger/S. Schüler/A. van der Haven (Hg.), Religion und Wahnsinn um 1900: Zwischen Pathologisierung und Selbstermächtigung/Religion and Madness Around 1900: Between Pathology and Self-Empowerment, Würzburg 2017 (Reihe Diskurs Religion), S. 251-273.

- Die Revolution. Auf den Spuren einer Dynamik des Umsturzes in Ernst Tollers Nachkriegsdramen, in: Links. Rivista di letteratura e cultura tedesca/Zeitschrift für deutsche Literatur- und Kulturwissenschaft 17 (2017), S. 45-55.

- Gustav Landauer, Lernt nicht Esperanto! (1907), in: Themenportal Europäische Geschichte 2017, www.europa.clio-online.de/quelle/id/artikel-4065.

- Hygiene, Rasse und Zukunftstechnik. Paolo Mantegazzas Beiträge zur Italianità, in: QFIAB 97 (2017), S. 316-338.

- Zwischen Gesetz und Technik. Die Feuerbestattungsfrage des 19. Jahrhunderts als Prisma italienisch-jüdischer Selbstverortung, in: S. Böhmer/C. Breuer/T. Müller- 
Bahlke/K. Tanner (Hg.), Technologien des Glaubens. Schubkräfte zwischen technologischen Entwicklungen und religiösen Diskursen. Acta Historica Leopoldina Nr. 71 (2017), S. 155-171.

\section{Nicole Kramer}

- Like a Solid Rock? Forces of Continuity and Silent Mutations within the Federal Republic of Germany's Welfare State Development, in: E. Eklund/M. Oppenheimer /J. Scott (Hg.), The State of Welfare. Comparative Studies of the Welfare State and the End of the Long Boom, 1965-1980, Oxford 2017, S. 151-175.

- Vers une coordination internationale de la politique du vieillissement: le Conseil de l'Europe et la République fédérale d’Allemagne dans les années 60, in: Revue d'histoire de la protection sociale 10 (2017), S. 84-101.

- Der Wandel des italienischen Sozialstaats in Zeiten politischer Umbrüche, in: QFIAB 97 (2017), S. 5-23.

\section{Heinrich Lang}

- Wissensdiskurse in der ökonomischen Praxis. Kaufmannbankiers als Experten der Märkte im 16. Jahrhundert, in: M. Füssel/Ph. Knäble/N. Elsemann (Hg.), Wissen und Wirtschaft. Expertenkulturen und Märkte vom 13. bis zum 18. Jahrhundert, Göttingen 2017, S. 141-168.

\section{Amedeo Osti Guerrazzi}

- Italians at war. War and War Experience in Fascist Italy, in: Journal of Modern Italian Studies 12/2017, S. 589-605.

- La persecuzione degli ebrei a Roma. Carnefici e vittime, in: S. Haia Antonucci/ C. Procaccia (Hg.), Dopo il 16 ottobre. Gli ebrei a Roma tra occupazione, resistenza, accoglienza e delazioni (1943-1944), Roma 2017, S. 35-272.

- Antikommunismus im italienischen Faschismus, in: D. Rigoll/N. Frei (Hg.), Der Antikommunismus in seiner Epoche. Weltanschauung und Politik in Deutschland, Europa und den USA, Berlin 2017, S. 158-174.

- L'Historiographie de la Shoah en Italie. 1995-2015, in: Revue d'histoire de la Shoah (206), Mémorial de la Shoah, mars 2017, S. 25-45.

\section{Chiara Pelliccia}

- Intorno alla cantata. Pastori, pastorelle e fratelli di Loggia: genesi di due raccolte di canzonette, in: G. Giovani/S. Aresi (Hg.), La cantata da camera e lo stile galante. Sviluppi e diffusione della „nuova musica“ tra il 1720 e il 1760, Amsterdam 2017, S. 85-102, https://stilegalantedotorg.files.wordpress.com/2017/12/06.pdf.

- mit L. Miucci, Rassegna Bibliografica annuale per il 2016, con integrazioni per il 2015 e anni precedenti (Fonti Musicali Italiane 22), Roma 2017, S. 205-296.

- mit J. María Domínguez, Resoconto della conferenza di Arnold Witte, „Committenza senza gusto: i cardinali, le istituzioni e le arti tra Seicento e Settecento“, 
Terzo seminario PerformArt, École française de Rome, 5. 12. 2017, https://performart-roma.eu/it/event/seminario-ricerca-workshop-database-efr/.

Andreas Rehberg

- Martin Luther und die Wege zum Heil in den Frömmigkeitspraktiken in Rom um 1500, in: M. Matheus/A. Nesselrath/M. Wallraff (Hg.), Martin Luther in Rom. Die Ewige Stadt als kosmopolitisches Zentrum und ihre Wahrnehmung, Berlin-Boston 2017 (Bibliothek des Deutschen Historischen Instituts in Rom 132), S. 277-307.

- Gli stranieri a Roma in un fondo dell’Archivio Storico Capitolino (1507-1527), in: S. Cabibbo/A. Serra (Hg.), Venire a Roma, restare a Roma. Forestieri e stranieri fra Quattro e Settecento, Roma 2017, S. 15-34, http://romatrepress.uniroma3.it/ojs/ index.php/forestieri/article/view/1586/1576.

- Indicatori dell'ascesa sociale del clero canonicale e sinergie nella formazione di ecclesiastici e laici a Roma (secoli XIV-XV), in: La mobilità sociale nel Medioevo italiano. 5. Roma e la Chiesa (secoli XII-XV), a cura di C. Carbonetti Vendittelli e M. Vendittelli, Roma 2017 (I libri di Viella 256), S. 39-73.

- (Hg.), Ablasskampagnen des Spätmittelalters. Luthers Thesen von 1517 im Kontext, Berlin-Boston 2017 (Bibliothek des Deutschen Historischen Instituts in Rom 132).

- Einführung, in: ebd., S. IX-XVII.

- „Ubi habent maiorem facultatem ... quam papa“. Der Heilig-Geist-Orden und seine Ablasskampagnen um 1500, in: ebd., S. 219-270.

- Geistliche Gnaden aus Rom. Anmerkungen zum päpstlichen Ablasswesen um 1500, in: Die Päpste der Renaissance. Politik, Kunst und Musik, hg. von M. Matheus, B. Schneidmüller, St. Weinfurter, A. Wieczorek, Regensburg 2017 (Die Päpste 2), S. 123-151.

- Quando i malati del Santo Spirito andavano alle terme. Qualche episodio legato ai Bagni di Stigliano alla fine del Quattrocento, RR. roma nel rinascimento 2016, S. 307-325.

- mit A. Cavallaro und A. Esposito, Donne di pietra: immagini, vicende, protagoniste delle sepolture romane del Rinascimento: premessa, in: Mélanges de l'École française de Rome. Moyen-Âge 127,1 (2015), S. 5-7, http://mefrm.revues.org/2406.

- Aspetti araldici delle sepolture femminili romane del Rinascimento, in: ebd., S. 35-46, http://mefrm.revues.org/2406.

Angela Steinsiek

- Das epistolarische Werk von Ferdinand Gregorovius. Eine Bestandsaufnahme, in: QFIAB 97 (2017), S. 290-315.

- „ „... er suchte alles zu bejahen“. Jean Paul und sein Verleger Cotta, in: H. Mojem/ B. Potthast (Hg.), Johann Friedrich Cotta (1764-1832). Verleger, Unternehmer, Technikpionier, Marbach am Neckar-Stuttgart 2017 (Beihefte zum Euphorion 98), S. 105-116. 


\section{Carlo Taviani}

- Il Banco genovese di San Giorgio prima corporation?, in: A. Giardina/E. Betta/ M. P. Donato/A. Feniello (a cura di), Storia mondiale dell'Italia, Roma-Bari 2017, S. 357-361.

- A Privatized State: Discourses on the Bank of San Giorgio (1446-1562), in: D. Bornstein/L. Gaffuri/B. J. Maxson (a cura di), Language of Power in Italy (1300-1600), Turnhout 2017, S. 49-64.

- La Casa de San Giorgio de Génova y los orígenes de las corporations europeas en la Edad Moderna, in: M. Herrero Sánchez (ed.), Repúblicas y republicanismo en la Europa moderna (siglos XVI-XVIII), México D. F. 2017, S. 507-528.

- The Genoese Bank of San Giorgio as a Micro Economic Nodal System, in: W. Blockmans/M. Krom/J. Wubs-Mrosezwicz (ed.), The Routledge Handbook of Maritime Trade Around Europe, Routledge 2017, S. 177-191.

Jörg Voigt

- Erfurt und Rom. Päpstliche Privilegien für die Bettelorden, in: K. Heinemeyer/ A. Hartinger (Hg.), Barfuss ins Himmelreich? Martin Luther und die Bettelorden in Erfurt, Dresden 2017, S. 80-83.

- Bettelorden und religiöse Frauen in Erfurt, in: ebd., S. 84-87.

\section{Kordula Wolf}

- mit K. Herbers (Hg.), Southern Italy as Contact Area and Border Region during the Early Middle Ages. Religious-Cultural Heterogeneity and Competing Powers in Local, Transregional and Universal Dimensions, Köln 2018 (Beihefte zum Archiv für Kulturgeschichte 80) [erschienen 2017].

- mit K. Herbers, (Re-)Thinking Early Medieval Southern Italy as a Border Region, in: ebd., S. 9-37.

- mit M. Di Branco, „(...) Capuamque primariam universam redegit in cinerem“. Il mito della distruzione di Capua antica nell'841, in: F. Marazzi (a cura di), Felix Terra. Capua e la Terra di Lavoro in età longobarda (secc. VIII-XI), Cerro a Volturno (IS) 2017 (Studi Vulturnensi 9), S. 195-206. 


\section{Vorträge, Lehre, Mitgliedschaften und Auszeichnungen der Institutsmitarbeiter/-innen}

\section{Vorträge}

Andreea Badea

- Zensur in der Frühen Neuzeit: Winter School des Historischen Seminars der Ludwig-Maximilians-Universität München, DHI Rom 26.1.

- „Cerco di stabilire, e di ordinare, per me, e per altrui la verità delle istorie“. Francesco Bianchini zwischen Gelehrsamkeit und Ämterjagd: Tagung „Gelehrte Praktiken in der Erforschung der Vergangenheit in der Frühen Neuzeit“, Hamburg 25. 3.

- The Roman Church and its Practices of Knowledge Control: Workshop des Descartes Theme Group „Borders and the Transfer of Knowledge“, Utrecht 16. 6.

- Wahrheitsanspruch und Wissensautorität. Rom und die katholische Historiographie im Zeitalter der Kritik: Kolloquium der Lehrstühle für Mittelalterliche Geschichte und Geschichtliche Landeskunde der Universität Trier 12. 7.

- La riforma in Europa. Riflessioni sulla delimitazione tra „evento“ e „fenomeno“: Studientag „Lutero e la formazione dell’Europa“, Università degli Studi di Roma „Tor Vergata“ 10. 10.

- Für wen zensiert wird. Die Indexkongregation und ihr Anspruch auf Autorität gegen die „superbia di certi cervelli“: Kolloquium des Lehrstuhls für Geschichte der Frühen Neuzeit der Universität Tübingen 27. 11.

- Making Truth - Administrating Truth. Establishing Credibility in Early Modern History: Tagung „Making Truth - Administrating Truth. Establishing Credibility in Early Modern History“, DHI Rom 15. 11.

- Defining Past and Present - Hagiographical Debates and Historical Criticism in 17th Century Rome: Tagung „Making Truth - Administrating Truth. Establishing Credibility in Early Modern History“, Academia Belgica di Roma 16. 11.

Martin Baumeister

- Welcome: International Workshop „Semantics of Space: Conceptual History Perspectives“, DHI Rom 23. 1.

- Southern Europe as a Discursive Construction: International Workshop „Semantics of Space: Conceptual History Perspectives“, DHI Rom 23. 1.

- Saluti: Sitzung des Direttivo Siscalt, DHI Rom 23.1.

- Begrüßung: Doktorandenexkursion der Ludwig-Maximilians-Universität München, DHI Rom 26. 1.

- Begrüßung: Winter School „Die Levante als Kontaktform zwischen Europa und dem Orient“ der Universität des Saarlandes, DHI Rom 30.1. 
- Welcome, Chair und Discussant: Workshop „Mapping Entaglements. Dynamics of Missionary Knowledge and ,Materialities“ across Space and Time (16th-20th centuries)“, DHI Washington 10. 2.

- Begrüßung: Winterschool der Ludwig-Maximilians-Universität München ,,,Katholizismus und Moderne‘- Zur Kulturbedeutung ihres Verhältnisses im Vergleich zwischen Deutschland und Italien“, DHI Rom 13. 2.

- Begrüßung: Studientag „Leibniz, Jablonski und Berlin, ein Seminär des LeibnizKorrespondenten Projekte“, DHI Rom 27. 2.

- Geschichte, Fiktion, Imagination: Gespräch mit Christoph Poschenrieder über dessen Roman „Das Sandkorn“, Historisches Kolleg, München 13. 3.

- Begrüßung: Institutsinterner Workshop „Perspektiven für die Endredaktion des Repertorium Germanicum (Bd. X: Sixtus IV.)“, DHI Rom 16. 3.

- Begrüßung, Einführung und Kommentar: Internationales Fachgespräch „Menschenrechte in der katholischen Kirche. Historische, systematische und praktische Perspektiven“, DHI Rom 22. 3.

- Organisation und Leitung: Gemeinsamer Studienkurs „Rom als Palimpsest“ mit der Bibliotheca Hertziana - Max-Planck-Institut für Kunstgeschichte und dem Deutschen Archäologischen Institut, Rom 3.-9. 4.

- Begrüßung: Internationale Tagung „Ethische Debatten und urbane Praxen“, DHI Rom 10. 4.

- Saluto: Colloquio „Alleati contro il Bolscevismo“. La guerra in Russia della divisione „Azul“ e dell’ARMIR, 1941-1944. Storia e memoria“, DHI Rom 27. 4.

- Welcome: International Workshop „The Making of the Italian Welfare State: National Specifities and European Entanglements“, DHI Rom 4. 5.

- Saluto: Giornata di Studi „Musica e pace. Nuove ricerche sull'età moderna“, DHI Rom 17. 5.

- Begrüßung: Wissenschaftliche Exkursion und Symposium der Jungen Akademie Mainz, DHI Rom 19. 5.

- Planung und Leitung: Internes Seminar der wissenschaftlichen Mitarbeiter/innen des DHI Rom, Norma 22.-23. 5.

- Leitung und Moderation: Sommerschule „Zwischen Nation und Religion: Kollektive Identitäten im Spannungsfeld von sozialen Konflikten, konfessioneller Vielfalt und politischer Macht“ des Internationalen Graduiertenkollegs „Religiöse Kulturen im Europa des 19. und 20. Jahrhunderts“ der Ludwig-MaximiliansUniversität München, Posen 11.-16. 6.

- Begrüßung Romexkursion des Historischen Vereins Niedersachsen, DHI Rom 20. 6 .

- Begrüßung: International Conference „Gender - Nation - Emancipation. Women and Families in the ,long' Nineteenth Century in Italy and Germany“, DHI Rom 22. 6 .

- Welcome: International Workshop „Going Native or Remaining Foreign? Catholic Missionaries as Local Agents in Asia (17th to 18th Centuries)“, DHI Rom 1. 7. 
- Vorstellung des DHI Rom: Fachgespräch der DFG über bestehende deutsch-italienische Wissenschaftskooperationen im Bereich der Geistes- und Sozialwissenschaften und Perspektiven zu deren Intensivierung und möglichem Ausbau, Deutsches Archäologisches Institut Rom 13. 7.

- Begrüßung: Summer School der Regesta Imperii, DHI Rom 4. 9.

- Planung und Leitung des Studienkurs Rom 2016: Studienkurs des DHI Rom für fortgeschrittene Studenten und Doktoranden des Faches Geschichte, 10.-19.9.

- Begrüßung: Wissenschaftliche Exkursion des Max-Planck-Instituts für europäische Rechtsgeschichte und gemeinsamer Workshop, DHI Rom 4. 10.

- Begrüßung und Vorstellung der Liegenschaft: Besuch der Staatssekretärin des BMBF Frau Cornelia Quennet Thielen, DHI Rom 4. 10.

- Discussant: Tagung „Gefährdete Demokratie? Deutschland und Italien zwischen Finanzkrise, Zuwanderung und Europaskepsis“, Kompetenzzentrum für Regionalgeschichte, Freie Universität Bozen 13.10.

- Planung und Leitung: Internes Seminar der wissenschaftlichen Mitarbeiter/innen des DHI Rom zur Vorbereitung der Evaluierung 2018, DHI Rom 26.-27. 10.

- Southern Thought oder brauchen wir eine südeuropäische (Zeit-)Geschichte?, Hamburger Institut für Sozialforschung, Hamburg 14. 11.

- Welcome: International Conference „Making Truth - Administrating Truth. Establishing Credibility in Early Modern History“, DHI Rom 15. 11.

- Buchvorstellung „Ragione e passione storica. Giuseppe Galasso e la storiografia europea“: Società Napoletana di Storia Patria, Neapel, 20.11.

- Die Deutschen in Rom und der Erste Weltkrieg: Öffentlicher Görres-Vortrag im Rahmen der Tagung „Päpstlichkeit und Patriotismus“, Campo Santo Teutonico, Vatikanstadt 22. 11.

- Discussant: Tagung „Penser la Mediterranée“, Forum Franco-Allemand de la Méditerranée, Aix en Provence 30.11.

Sabine Ehrmann-Herfort

- The Migration of Musical Terms in the Context of Different Cultural Spaces, International Workshop „Semantics of Space: Conceptual History Perspectives“, DHI Rom 24. 1.

- Vorstellung der Musikgeschichtlichen Abteilung und des Projekts „,Dass Gerechtigkeit und Friede sich küssen“: Repräsentationen des Friedens im vormodernen Europa“ anlässlich des Besuchs einer Studierendengruppe von Prof. Dr. Ferdinand Kramer, Prof. Dr. Dieter Weiß und Dr. Britta Kägler (Ludwig-MaximiliansUniversität München, Institut für Bayerische Geschichte), DHI Rom 26. 1.

- Bericht über den aktuellen Stand des musikwissenschaftlichen Teilprojekts: Arbeitstreffen Friedensrepräsentationen, Wolfenbüttel 30. 1.

- Introduzione sowie Come suona la pace? Modi di rappresentare la pace nella musica intorno al 1700: Studientag „Musica e pace. Nuove ricerche sull'Età moderna“, DHI Rom 17. 5. 
- Sulla migrazione dei concetti musicali nell'Europa della prima età moderna: Lehrveranstaltung von Prof. Cecilia Campa, Conservatorio di Musica Santa Cecilia, Rom 29. 5.

- Rom als internationale Musikstadt zur Händel-Zeit: Exkursion „Rom und die Deutschen vom Mittelalter bis ins 20. Jahrhundert“: Historischer Verein für Niedersachsen, Casa Valdese, Rom 22.6.

- Deutsche in der ,Hauptstadt der Welt‘ . Georg Friedrich Händel: Abendveranstaltung „Deutsche in der Hauptstadt der Welt - Bildende Kunst trifft Musik“ anläßlich der Ausstellung „Wunder Roms“, Diözesanmuseum, Paderborn 6. 7.

- Bericht über den aktuellen Stand des musikwissenschaftlichen Teilprojekts: Arbeitstreffen Friedensrepräsentationen, Mainz 25. 9.

- Bericht über die Arbeit der Musikgeschichtlichen Abteilung, Rückblick und Ausblick: Jahrestagung der Gesellschaft für Musikforschung, Sitzung der Kommission Auslandsstudien, Kassel 27.9.

- Friedensszenarien in Festmusiken Georg Philipp Telemanns: Internationales wissenschaftliches Symposium „Der Komponist als Chronist: Telemanns Gelegenheitsmusik als musikalisches Tagebuch“, Frankfurt am Main 6. 10.

- Saluto: Vortrag von Silke Leopold (Universität Heidelberg) und Projektpräsentation von Aaron Carpenè (Rom) und Stefano Vizioli (Rom/Pisa) anlässlich des 450. Geburtstags von Claudio Monteverdi, DHI Rom 11. 10.

Markus Engelhardt

- Begrüßung und Führung der Musikgeschichtlichen Abteilung: Studierende Conservatorio Nazionale di Musica „Santa Cecilia“, DHI Rom 28. 3.

- Organisation und Moderation: Vortrag Irmgard Scheitler „Lutherus redivivus: Zur Musikgeschichte frühneuzeitlicher Reformationsjubiläen“, DHI Rom 30. 3.

- Tagungsvorsitz: Giornate carissimiane 2017, Pontificio Istituto di Musica sacra, Rom 18. 4.

- Organisation und Moderation: Vortrag Siegfried Matthus, Herausforderung Reformationsjahr. Zur Dramaturgie meiner musikalischen Vision „Luthers Träume“ 2017, DHI Rom 11. 5.

- Tagungsvorsitz: Giornata di studi „Musica e pace. Nuove ricerche sull'Età moderna“, DHI Rom 17. 5.

- Begrüßung und Führung der Musikgeschichtlichen Abteilung: Studierende Universität Rom „Tor Vergata“ unter der Leitung von Teresa M. Gialdroni, DHI Rom 18. 5. und 7. 12. sowie Studienkurs Rom des DHI, DHI Rom 11. 9.

- Organisation und Begrüßung: Präsentation Bd. XVI der Reihe „Concentus musicus“ (Piccinni, „La buona figliuola“), DHI Rom 21. 9.

- Präsentation Grundsatzpapier Musikabteilung: Internes Seminar zur Evaluierung 2018, DHI Rom 26. 10. 
- Organisation, Moderation: Vortrag Thomas Schmidt „Failed, Rejected, Misunderstood? On the Misplaced Nature of Mendelssohn's „Reformation“ Symphony“, Musicologia oggi, DHI Rom 26. 10.

- Organisation und Moderation: Leitung und Komponistenstipendiaten der Villa Massimo besuchen die Musikgeschichtliche Abteilung, DHI Rom 9.11.

- Organisation: die Musikgeschichtliche Abteilung besucht die British School at Rome, British School at Rome 23. 11.

- Organisation und Moderation: Vortrag, Präsentation „Wachet recht auff“: Ralf Hoyer (Berlin) über sein Oratorium zum Luther-Jahr 2017, DHI Rom 7. 12.

Richard Erkens

- Ruolo e influenza di un impresario a Roma: Giuseppe Polvini Faliconti (1717-1741): Colloquia 2017, Università „La Sapienza“, Rom 8. 5.

- mit L. Scarlini, Le onde del destino: Alberto Franchetti e il Cristoforo Colombo a Genova: Concerto-conferenza, Biblioteca Universitaria, Genova 25. 5.

- The Death of an Impresario (and What it Tells Us about Opera Production in the 1740s): Konferenz „tosc@bern.2017.2nd transnational opera studies conference“, Universität Bern 5. 7.

- Stadtführung „Apollo an der Leine oder Die Oper in der Papststadt. Ein Rundgang zur wechselvollen Geschichte der öffentlichen Theater Roms“: Studienkurs Rom des DHI, Rom 16. 9.

- Stadtführung „Opera riaperta: Römische Theater im frühen 18. Jahrhundert“: Herbstführung des DHI Rom 17. 10.

- $\quad$ Einführung zu „My Cousin - Caruso (1918)“: Kinolektionen, DHI Rom 29.11.

Daniel Hedinger

- Beyond the master narrative? The Second World War in Trans-imperial Perspective: Workshop „In-Between Empires: Trans-imperial History in a Global Age“, Berlin 15. 9.

- mit H. Grandits, St. Kirmse und St. Rinke, Podiumsdiskussion „Wohlfahrt und Sicherheit“. Auftaktkonferenz „Diktaturen als alternative Ordnungen“ des interdisziplinären Verbunds für vergleichende Diktaturforschung an der HumboldtUniversität, Berlin 13. 10.

- Lost Legacies? The Axis, the Postcolonial and the Great Silence: Workshop „The Axis Powers and Decolonisation“, Berlin 14.12.

Jörg Hörnschemeyer

- mit J. Voigt, Das Repertorium Germanicum Online: Doktorandenexkursion Ludwig-Maximilians-Universität München, 26.1.

- mit A. Rehberg, Germania Sacra im europäischen Forschungsverbund II. Das Repertorium Germanicum am Deutschen Historischen Institut in Rom: Tagung „Geisteswissenschaftliche Großforschung gestern, heute, morgen. Paul Fridolin 
Kehr (1860-1944) und die Folgen. 100 Jahre Germania Sacra“, Akademie der Wissenschaften zu Göttingen, Göttingen 25. 2.

- mit A. Rehberg und J. Voigt, Das Repertorium Germanicum - Neue Auswertungsmöglichkeiten: Beiratssitzung, DHI Rom 4. 3.

- mit J. Voigt, Digital Humanities am DHI Rom: Wissenschaftliche Exkursion des Max-Planck-Instituts für europäische Rechtsgeschichte und gemeinsamer Workshop, DHI Rom 4. 10.

- Die Digital Humanities am DHI Rom im Evaluierungszeitraum 2011-2017: Internes Seminar zur Vorbereitung der Evaluierung 2018, DHI Rom 26. 10.

Lutz Klinkhammer

- Tra perdono e oblio: Podiumsdiskussion zum Thema „La Shoah dell'Arte: il perdono“, Galleria Nazionale d'Arte Moderna, Rom 26.1.

- Italia come potenza occupante nella Seconda Guerra Mondiale: Tagung „Caro Nemico. Soldati pistoiesi e toscani nella Resistenza in Albania e Montenegro 1943-1945“, Pistoia 10. 3.

- Grusswort: Tagung „Mappatura dei campi di lavoro in Italia 1943-1945“ der Associazione Topografia per la storia, Casa della memoria, Rom 28. 3.

- Quali Eroi? La Germania Federale e il confronto con il passato: Ausstellung „Baselitz“, Palazzo delle Esposizioni, Rom 29. 3.

- La ricerca sugli internati militari italiani in Germania: Università della Calabria, Cosenza 4. 4.

- La guerre comme expérience touristique? Les combattants allemands pendant la Deuxième guerre mondiale et leurs vues sur l'étranger: Tagung „Du ,Grand Tour“ à Erasmus: l'Europe au bout du voyage?“, Istituto Universitario Europeo, Florenz 7. 4.

- Kommentar: Tagung „Remedies against Immunity“, Villa Vigoni, Loveno di Menaggio 13. 5.

- Gli storici tedeschi e il discorso pubblico sul passato: Tagung „Capire la Germania“, Università degli Studi di Perugia, 16. 5.

- Präsentation des Buches von P. Pezzino/G. Fulvetti „Zone di guerra, geografie di sangue. L'Atlante delle stragi naziste e fasciste in Italia (1943-1945)“: Università degli Studi di Padova, 30. 5.

- Begrüßung: Tagung der Arbeitsgemeinschaft für die neueste Geschichte Italiens, Saarbrücken 15. 6.

- Podiumsdiskussionsbeitrag „Populismus“: Veranstaltung „Geisteswissenschaften im Dialog“, Akademie der Wissenschaften, Berlin 20.6.

- La storia degli Internati militari italiani - ricerche e stato dell'arte: Präsentation des Albo degli IMI caduti, Ministero degli Affari Esteri, Rom 27. 6.

- Diskussionsbeiträge im Rahmen des Doktorandenkolloquiums der Siscalt und der Villa Vigoni, Loveno di Menaggio 4.-5. 9. 
- Datenbanken zur Zeitgeschichte am DHI Rom: Studienkurs Rom des DHI, Rom 18. 9 .

- Mussolini - eine Revolutionäre Biographie?: Stiftungskonferenz der Max Weber Stiftung, DHI Moskau 21. 9.

- Beitrag zur Podiumsdiskussion „Der Historiker als Arzt“: Institut für Zeitgeschichte, München 28.9.

- Präsentation des „Portale Archivi della Resistenza“: Fondazione Gramsci - Montecitorio, Sala della Lupa, Rom 25. 10.

- Splendid isolation? Riflessioni sul contributo internazionale della storiografia contemporaneistica italiana: Tagung „Italia e Germania. Storiografie in dialogo incrociato“, Istituto Storico Italo-Germanico, Trient 22. 11.

- Diskussionsbeitrag „Italien und Deutschland. Akademischer, wissenschaflicher und kultureller Austausch. Europäische Herausforderungen und Perspektiven“: DAAD-Alumni-Treffen, Università degli Studi di Roma Tre, Rom 1. 12.

- L'esilio tedesco 1933-1945“: Università degli Studi di Padova, 6. 12.

- Gli Internati militari italiani in Germania: Auditorium Diocesano, Frosinone 14. 12.

Alexander Koller

- I grandi poteri dell’Impero e Lutero: Tagung „Lutero 500 anni dopo. Una rilettura della Riforma luterana nel suo contesto storico ed ecclesiale“, Comitato Pontificio per le Scienze Storiche, Rom 29. 3.

Carolin Kosuch

- Ein missratener Sohn? Gustav Landauer zwischen jüdischem Bürgertum und Anarchismus: Erich Mühsam Tagung „Missratene Söhne?! Generationskonflikte als Gesellschaftskritik“, Bad Malente 22. 9.

- Moderne und Asymmetrie: Ein deutsch-italienischer Vergleich: Incontro di studi „Germania/Italia, lontane/vicine nazioni a confronto e orizzonti della modernità in occasione della pubblicazione del libro di Christof Dipper ,Ferne Nachbarn““, Biblioteca di Ricerca di Area Umanistica, Neapel 25. 10.

- Konkurrierende Befreiungsprogramme? Anarchismus und Vegetarismus auf dem Monte Verità: Internationale Tagung „Tra Ribellione e Conservazione. Monte Verità e la Cultura Tedesca“, Istituto Italiano di Studi Germanistici/Istituto Svizzero, Rom 29. 11.

- Radiointerview zum Monte Verità: Deutschlandfunk Kultur heute, 30. 11., tanzen_im_tessin_einetagung_zur_kuenstlerkolonie_monte_dlf_20171130_1751_ 82218939.mp3. 


\section{Nicole Kramer}

- A close look at the history of the Italian welfare state. Introduction. Tagung „The making of the Italian welfare regime: National specificities and European entanglements“, DHI Rom 4. 5.

- La Germania nel secondo dopoguerra e il Welfare. Tagung „Capire la Germania“, Università degli Studi di Perugia 16. 5.

\section{Gerhard Kuck}

- Stadtteilführung durch die Garbatella, Studienkurs Rom des DHI, Rom 18. 9.

\section{Heinrich Lang}

- Warum Bankiers Herrscher finanzieren. Staatsbankrotte, Wechsel- und Kreditmärkte um 1550: Oberseminar an der Universität Göttingen 31. 1.

- Projektvorstellung: Beiratssitzung, DHI Rom 4. 3.

- Projektvorstellung: Mittwochsvortrag, DHI Rom 26. 4.

- Italienische Kaufmannbankiers und die Bankrotte der Könige. Finanzmärkte Europas im 16. Jahrhundert: Goethe-Universität, Frankfurt am Main 2. 5.

\section{Amedeo Osti Guerrazzi}

- Axis Wars: Internationale Tagung „Fascist Wars“, Konstanz 7. 6.

- Italian Fascism at War: Internationale Tagung „Fascist Warfare. A Concept to Understand Fascism and Total War in the First Half of Twentieth Century“, Barcellona 16. 3.

\section{Chiara Pelliccia}

- Bericht über den aktuellen Stand des musikwissenschaftlichen Teilprojekts: Arbeitstreffen Friedensrepräsentationen, Wolfenbüttel 30.1.

- Projektvorstellung: Beiratssitzung, DHI Rom 4. 3.

- Riflessi della pace di Rijswijk sul mare di Anzio. Cantata e apparati per la visita di Innocenzo XII all'antico porto neroniano (1697): Studientag „Musica e pace. Nuove ricerche sull'età moderna“, DHI Rom 17. 5.

- Projektbericht: Studientag „Musica e pace. Nuove ricerche sull’Età moderna“, DHI Rom 18. 5.

- Politica, rivolte e violenza. Riflessi nel lamento per musica secentesco: Colloque international „La violence dans la révolte. Expériences politiques et pratiques culturelles“, École française de Rome, 12. 6.

- Bericht über den aktuellen Stand des musikwissenschaftlichen Teilprojekts: Arbeitstreffen Friedensrepräsentationen, Mainz 25. 9.

- Materiali e annotazioni per la mostra virtuale: Arbeitstreffen Friedensrepräsentationen, Mainz 6. 12. 


\section{Andreas Rehberg}

- mit J. Hörnschemeyer und J. Voigt, Einführung in das Repertorium Germanicum: Winter School der Ludwig-Maximilians-Universität München, DHI Rom 21. 2.

- mit J. Hörnschemeyer, Germania Sacra im europäischen Forschungsverbund II. Das Repertorium Germanicum am Deutschen Historischen Institut in Rom: Tagung „Geisteswissenschaftliche Großforschung gestern, heute, morgen. Paul Fridolin Kehr (1860-1944) und die Folgen. 100 Jahre Germania Sacra“, Akademie der Wissenschaften zu Göttingen, Göttingen 25. 2.

- L'impatto dell'araldica religiosa nell'autorappresentazione aristocratica a Roma e in Lazio (1500-1630): $1^{\circ}$ Convegno internazionale „L’araldica religiosa nella Galleria dei Papi di palazzo Altieri e nell'arte di ogni tempo e paese“, Centro Studi Araldici (Varese), Oriolo di Roma 13. 5.

- Stranieri in cerca di un notaio a Roma: scelte e convenienze: Studientag „Notai a Roma. Notai e Roma. Società e notai a Roma tra Medioevo ed età moderna“, Archivio di Stato, Rom 30. 5.

- mit J. Voigt, Einführung in das Repertorium Germanicum: Summer School der Regesta Imperii, DHI Rom 5. 9.

- mit J. Voigt, Einführung in das Repertorium Germanicum: Studienkurs Rom des DHI und Besuchergruppe des Melanchthon-Zentrums unter Prof. Martin Wallraff, DHI Rom 14. 9.

- Domenico Jacovacci, ovvero l'esempio di una famiglia romana in ascesa sociale tramite lo studio del diritto: Internationale Tagung „Early Modern Rome 3, 13411667“, University of California-Rome Study Center, Biblioteca Vallicelliana, Rom 5. 10.

- Führung im Palazzo Colonna: Besuch des Freundeskreises des DHI, Rom 6. 10.

- Einführung in das Repertorium Germanicum: Medieval History Seminar, German Historical Institute London and the German Historical Institute Washington D.C., London 13. 10.

- Römische Quellen für deutsche Rom-Besucher um 1500: „Ulrich von Hutten und Rom. Deutsche Humanisten in der Ewigen Stadt am Vorabend der Reformation“: Jahrestagung der Willibald-Pirckheimer-Gesellschaft, DHI Rom 9. 11.

- Le ricadute del Grande Scisma per la vita culturale del baronato romano - il caso dei Colonna: Tagung „La linea d’ombra. Roma 1378-1417“, Université de Lausanne, Faculté des Lettres, Lausanne 8. 12.

- Gestire l'assistenza: l'ospedale di Santo Spirito e l'ospedale del Salvatore a confronto: Tagung „Vivere la città. Roma nel Rinascimento“, Università di Roma „La Sapienza“, Dipartimento di Storia Culture Religioni, Rom 16.12. 
Franziska Rohloff und Dorothea Wohlfahrt

- Projektvorstellung: Besuch der Staatssekretärin des BMBF Cornelia QuennetThielen, DHI Rom 4. 10.

- Projektvorstellung: Wissenschaftliche Exkursion des Max-Planck-Instituts für europäische Rechtsgeschichte und gemeinsamer Workshop, DHI Rom 4. 10.

- Projektvorstellung: Abteilungsleiterkonferenz, Deutsches Archäologisches Institut Rom 7. 12.

\section{Carlo Taviani}

- Genoese Merchant Networks in Africa and America (15th-16th centuries): Internationale Tagung „Crossroads Africa: Networks and Global Exchange (1250-1750)“, Villa I Tatti (Harvard), Fiesole 12. 1.

- In the Shadow of Other Empires: Genoese Merchant Networks and their Conflicts across the Atlantic Ocean (ca. 1450-1530): Internationale Tagung „Conflicts and their Resolution in Atlantic Europe (13th-17th Centuries)“, Universidad de La Laguna, Tenerife 21. 4.

- The Genoese Slave Trade (15th-16th Centuries): University of Newcastle (Australien) 18. 8.

- mit St. Teasdale, Genoese Merchant Networks from the Black Sea to West Africa and the Americas (15th-16th Centuries): International ENIUGH Conference, Budapest 30. 8 .

Jörg Voigt

- mit J. Hörnschemeyer, Das Repertorium Germanicum Online: Doktorandenexkursion Ludwig-Maximilians-Universität München, 26. 1.

- Reformen von Frauenklöstern im Spiegel der kurialen Überlieferung. Zu den Auswertungsmöglichkeiten des Repertorium Germanicum und des Repertorium Poenitentiariae Germanicum: Internationale Tagung „Reformen von geistlichen Frauengemeinschaften im Mittelalter“, Akademie der Diözese Rottenburg-Stuttgart, Weingarten 24. 3.

- Confessors and confession in the curial registers: Panel „Confession in the Middle Ages, II: After the Fourth Lateran Council, 1215“, International Medieval Congress, University of Leeds 4. 7.

- mit A. Rehberg, Das Repertorium Germanicum: Summer School der Regesta Imperii, DHI Rom 6. 9.

- mit A. Rehberg, Das Repertorium Germanicum: Studienkurs Rom des DHI, Rom 14. 9.

- mit J. Hörnschemeyer, Digital Humanities am DHI Rom: Wissenschaftliche Exkursion des Max-Planck-Instituts für europäische Rechtsgeschichte und gemeinsamer Workshop, DHI Rom 4. 10.

- Diskutant bei der Herbsttagung 2017 des Konstanzer Arbeitskreises für mittelalterliche Geschichte e. V., Insel Reichenau 10. 10. 
Kordula Wolf

- Leitung mit Prof. Dr. H. Schlange-Schöningen (Universität des Saarlandes) und Prof. Dr. P. Thorau (Universität des Saarlandes) der vom Historischen Institut der Universität des Saarlandes am DHI veranstalteten Winter School „Die Levante als Kontaktraum zwischen Europa und dem Orient“, DHI Rom 30.1.-3. 2.

- Ostia und Porto im Mittelalter: Winter School „Die Levante als Kontaktraum zwischen Europa und dem Orient“", Ostia Antica (Rom) 31.1.

- Cremona and Venice as Trojan Cities. 12th/13th-Century Urban Historiography Changing Narratives, Intertextual Relations, Historical Contexts: Tagung „Troie en Europe au Moyen Âge“, Paris 6. 4.

- mit Cl. Gantner (Universität Wien) Organisation von drei Sessions zum Thema „Othering in Pre-Norman Southern Italy, I: Perceptions and Contexts, II: Otherness in Culturally Divergent Societies, III: Non-Christians and Non-Muslims as a Challenge“, International Medieval Congress, Leeds 3.-6. 7.

- „Practices of Othering the ,Saracens“ in 9th-Century Mainland Italy and Sicily“: International Medieval Congress, Leeds 6. 7.

- Impulsreferat zum Methoden-Workshop „Herausforderungen durch die Transnationalisierung “, MPI-Workshop, DHI Rom 4.10.

- Führung „SS. Quattro Coronati und mittelalterlicher Laterankomplex“: Studienkurs Rom des DHI, Rom 12.9.

\section{Lehre von Institutsmitarbeiter/-innen}

Andreea Badea

Hauptseminar „Die Reformation in Europa“, Wintersemester 2017/18, Historisches Seminar der Universität Hamburg.

Sabine Ehrmann-Herfort

Blockseminar: „Musiktheater nach 1950 - Positionen und Werkbeispiele“, Sommersemester 2017, Musikwissenschaftliches Seminar Detmold/Paderborn.

Richard Erkens

Blockseminar „Das Theater hinter den Kulissen: Metatheatralität im (italienischen) Musiktheater“, Wintersemester 2016/17, Institut für Musikwissenschaft und Medienwissenschaft, Humboldt Universität Berlin.

Lutz Klinkhammer

Blockseminar „Längsschnitt / Internationale Geschichte: Das europäische Zeitalter der Emanzipation der Juden und seine Gegner, 1750-1850“, Sommersemester 2017, Johannes-Gutenberg Universität Mainz. 
Carolin Kosuch

Blockseminar „Die Revolution. Geschichtsphilosophie(n) des Anarchismus“, Sommersemester 2017, Technische Universität Braunschweig.

Gerhard Kuck

Studienkurs zu Theorie und Praxis der Übersetzung im Rahmen der Laurea triennale, Scuola Superiore di Mediazione linguistica San Domenico, Rom, akademisches Jahr 2016/17 (1. und 2. Studienjahr), akademisches Jahr 2017/18 (1., 2. und 3. Studienjahr).

\section{Mitgliedschaften und Auszeichnungen}

Sabine Ehrmann-Herfort wurde in das Comitato Scientifico des Ensembles Ghislieri Choir \& Consort (Pavia) aufgenommen.

Lutz Klinkhammer wurde in das Comitato scientifico der „Annali dell'Istituto storico italo-germanico“ in Trient aufgenommen.

Kordula Wolf wurde in den Editorial Board der Zeitschrift „Journal of Transcultural Medieval Studies“ aufgenommen.

\section{Kooperationen}

\section{Zusammenarbeit innerhalb der Stiftung}

Das römische DHI pflegt vielfältige Kooperationen auf Stiftungsebene, die sich von Forschungsprojekten über Tagungen bis in den Bereich der historischen Fachinformatik erstrecken. Im Bereich der historischen Datenverarbeitung spielt das DHI London weiterhin eine besondere Rolle. Außerdem ist das DHI auf Stiftungsebene an der Publikationsplattform perspectivia.net sowie an diversen Arbeitskreisen, u.a. dem Arbeitskreis Digital Humanities, beteiligt. Im Rahmen einer Kooperation mit dem DHI Washington wurde eine Tagung zum Thema „Mapping Entanglements. Dynamics of Missionary Knowledge and ,Materialities‘ across Space and Time (16th-20th Centuries)“ in Washington organisiert. Überdies beteiligte sich das römische DHI an der Stiftungskonferenz der Max Weber Stiftung zum Thema „Revolutionäre Biographien“ in Moskau. In dem unter maßgeblicher Beteiligung des DHI London organisierten neuen International Centre of Advanced Studies „Metamorphoses of the political“ fungiert das römische DHI als Kooperationspartner im Themenmodul „History as a political category“. 


\section{Weitere Kooperationen}

Kooperationen mit Universitäten, mit Schwerpunkten in Deutschland und Italien, sind im Rahmen der Institutsaktivitäten besonders relevant. Im Berichtszeitraum wurden am römischen DHI mehrere große Tagungen in enger Zusammenarbeit mit deutschen und ausländischen Universitäten durchgeführt. Dazu gehörten u. a. die Universitäten Bern, Gent, Leeds, München, Münster, Södertörn Stockholm und Stuttgart, im Gastland die Universitäten Perugia und Ca' Foscari Venedig sowie die drei großen staatlichen Universitäten Roms. Eine besondere Rolle spielten Studienkurse in Form von Winter- und Sommerschulen, die in Zusammenarbeit mit deutschen Universitäten, im Berichtzeitraum mit der Universität des Saarlandes Saarbrücken sowie den Universitäten Erlangen-Nürnberg und München, durchgeführt wurden. Fortgeführt wurde die enge Zusammenarbeit mit der Società Italiana per la Storia Contemporanea dell'Area di Lingua Tedesca SISCALT und ihrem deutschen Gegenstück, der Arbeitsgemeinschaft für die neueste Geschichte Italiens. In der italienischen Hauptstadt pflegen das Institut und seine Mitarbeiter/-innen intensive Kontakte zu den deutschen Partnerinstituten wie überhaupt zu den in der Unione degli Istituti di Archeologia, Storia e Storia dell'Arte di Roma zusammengeschlossenen Forschungseinrichtungen. Das römische DHI beteiligt sich an dem im Berichtsjahr neu initiierten „Modern Italy Seminar“ der Unione. Überdies wurden Veranstaltungen zusammen mit dem Deutschen Archäologischen Institut, der Bibliotheca Hertziana, der Academia Belgica, der École française de Rome und dem Istituto Svizzero di Roma organisiert. DHI, das Deutsche Archäologische Institut und die Bibliotheca Hertziana zuzüglich der Villa Massimo kooperieren in einem gemeinsamen, vom Auswärtigen Amt und der Max Weber Stiftung finanzierten Forschungsprojekt zur Geschichte der deutschen Forschungs- und Kultureinrichtungen in Rom vom Ersten Weltkrieg bis in die 1960er Jahre im Spannungsfeld zwischen Wissenschaft und Politik, das im Berichtszeitraum nach einer Anschubphase mit zwei Doktorandinnen gestartet wurde. Überdies führten die drei deutschen Forschungsinstitute in Rom zum ersten Mal einen gemeinsamen interdisziplinären Studienkurs für fortgeschrittene Studierende zum Thema „Rom als Palimpsest“ durch.

Wie oben bereits erläutert, bestehen wichtige Kooperationen ebenfalls im Bereich der historischen Datenverarbeitung. Das DHI ist Mitglied der digitalen Forschungsinfrastruktur für die Geistes- und Kulturwissenschaften DARIAH-DE sowie der web- und zentrenbasierten Forschungsinfrastruktur CLARIN-D. Im Berichtszeitraum wurde die Zusammenarbeit in langfristigen Editionsvorhaben des DHI London sowie des Seminars für mittlere und neuere Kirchengeschichte der Universität Münster und des Instituts für Zeitgeschichte in München fortgesetzt. Das neu initiierte DFG-Projekt der Briefedition von Ferdinand Gregorovius wird auf DH-Ebene in Zusammenarbeit mit der Berlin-Brandenburgischen Akademie der Wissenschaften durchgeführt.

Die Musikgeschichtliche Abteilung hat die Arbeit am Projekt des Leibniz-Instituts für Europäische Geschichte in Mainz „,,Dass Gerechtigkeit und Friede sich küssen“ Repräsentationen des Friedens im vormodernen Europa“ fortgeführt. 
Wissenschaftler/-innen des Instituts nahmen Lehraufträge an den Universitäten Berlin (HU: Richard Erkens), Braunschweig (Carolin Kosuch), Detmold-Paderborn (Sabine Ehrmann-Herfort), Hamburg (Andreea Badea) und Mainz (Lutz Klinkhammer) sowie an der Scuola Superiore di Mediazione linguistica San Domenico in Rom (Gerhard Kuck) wahr. Martin Baumeister war im Berichtszeitraum weiterhin Mitglied des Internationalen Graduiertenkollegs „Religiöse Kulturen im Europa des 19. und 20. Jahrhunderts“ der Ludwig-Maximilians-Universität München, der Karls-Universität Prag und der Universität Poznań und beteiligte sich an der Organisation und Durchführung einer Sommerschule des IGK in Poznań.

\section{Historische und Musikgeschichtliche Bibliothek}

Die beiden Bibliotheken des DHI Rom - Musikbibliothek und Historische Bibliothek wurden Ende Juni 2017 organisatorisch unter der Leitung von Patricia Kern zusammengefasst: Es wurden die Aufgabenbereiche des Personals angeglichen und erste Geschäftsgänge angepasst. Die Kommunikation zwischen allen Mitarbeitern/-innen der Abteilung wurde durch die Einführung regelmäßiger Sitzungen und eines internen Bibliotheksportals (basierend auf Wiki-Technologie) verbessert. Des Weiteren wurden die lange anstehende Modernisierung der Bibliotheks-IT eingeleitet: Ab Januar 2018 werden die beiden noch auf DOS basierenden allegro-Systeme durch ein gemeinsames, von der Zentrale des Südwestdeutschen Bibliotheksverbundes (SWB) gehostetes Bibliotheksmanagementsystem (Koha) abgelöst, das 2017 von den Mitarbeitern/-innen des DHI Rom konfiguriert wurde. Damit steht ein modernes Bibliotheksmanagementsystem zur Verfügung - mit einer Benutzerverwaltung, einer Fremddatenübernahme (SWB) und einer integrierten Erwerbung und Katalogisierung aller Medien, auch der E-Medien. Seit Juli 2017 katalogisiert das DHI Rom seine Bestände im Verbundkatalog des SWB, seit Dezember werden die Zeitschriften in der ZDB nachgewiesen. Somit wurde der Anfang gemacht, die Bestände des DHI Rom überregional sichtbar zu machen. Seit November 2017 werden auch die Bestände der Musikabteilung im römischen Verbundportal URBiS nachgewiesen. Die Umstellungen wurden von intensiven Schulungen der Mitarbeiter/-innen in den neuen Bibliotheksstandards begleitet.

\section{Bestandserhaltung}

Ein weiteres großes Aufgabengebiet war im Berichtzeitraum die Bestandserhaltung: Im Sommer 2017 wurde in drei Magazinen des Historischen Lesesaals Schimmelbefall festgestellt, so dass die Magazine für die Benutzer gesperrt werden mussten. Das dritte Magazin ist komplett gesperrt. Das Schimmelproblem betrifft ungefähr zwei Drittel des Bestandes. 
Ursache für den starken Schimmelausbruch ist eine Kombination aus klimatischen Herausforderungen, technischen Schwierigkeiten mit den Klimaanlagen sowie einer starken Verschmutzung der Bestände. Das DHI Rom plant einen Umbau und eine Modernisierung der Liegenschaft, bei der auch notwendige Modernisierungen der Klimatechnologie vorgenommen werden sollen. Die Lösung des Schimmelproblems der Bibliothek kann nur in Zusammenhang mit dieser Modernisierung erfolgen und ist dementsprechend nicht kurzfristig umzusetzen. Für 2018 ist die Reinigung aller Bestände geplant, verbunden mit einer teilweisen Auslagerung betroffener Bestände. Ein zweites Arbeitsgebiet der Erhaltung war der Altbestand, der ca. 6000 Bücher aus den Jahren von 1504 bis 1850, teilweise in schlechtem konservatorischem Zustand, umfasst. Zu Rate gezogen wurde die Chefrestauratorin der HerzogAugust-Bibliothek Wolfenbüttel, die sich einen Überblick über die Situation in den Magazinen des DHI verschaffte, wertvolle Hilfe bei der Planung der notwendigen Restaurierungsmaßnahmen leistete und alle Mitarbeiter/-innen im Umgang mit dem Altbestand schulte. Eine italienische Restauratorin nahm erste Sicherungsmaßnahmen vor und führte eine Schadenserhebung durch. Die Benutzung der Altbestände wurde den besonderen Bedürfnissen der Medien angepasst, die fortan nur noch im Lesesaal konsultiert werden können. Das dritte Aufgabengebiet der Bestandserhaltung war die Beseitigung problematischer Lagerungsbedingungen. So konnten u. a. von ca. 7000 seit 20 Jahren in Kisten lagernden Büchern ca. 2500 Bände sachgerecht aufgestellt und katalogisiert werden.

\section{Nachwuchsförderung: Praktika und Stipendien}

Das Institut bot im Berichtszeitraum 13 Praktikumsplätze in der Geschichtswissenschaft, 2 Praktikumsplätze in der Musikgeschichte sowie 3 Praktikumsplätze in der Verwaltung an. Die individuellen Praktika erstreckten sich über einen Zeitraum von 6 Wochen bzw. 2-3 Monaten in der Verwaltung. Die Mehrzahl der Praktikanten/-innen erhielt ein DAAD-Kurzzeitstipendium.

In der folgenden Liste sind die Praktikanten/-innen namentlich angeführt mit Angabe ihrer Universität und ihrem Forschungsschwerpunkt.

\begin{tabular}{|c|c|c|c|}
\hline 9. 1.-17. 2. 2017 & Charlotte Bastam & Universität München & Zeitgeschichte \\
\hline 9. 1.-17. 2. 2017 & Philipp Henning & $\begin{array}{l}\text { Humboldt Universität } \\
\text { Berlin }\end{array}$ & Zeitgeschichte \\
\hline 20. 2.-31. 3. 2017 & $\begin{array}{l}\text { Maximilian } \\
\text { Heumann }\end{array}$ & Universität München & Zeitgeschichte \\
\hline 20. 2.-31. 3. 2017 & $\begin{array}{l}\text { Simon } \\
\text { Siemianowski }\end{array}$ & Universität Bologna & Frühe Neuzeit \\
\hline
\end{tabular}




\begin{tabular}{|c|c|c|c|}
\hline 20. 3.-19. 5. 2017 & Patricia Wosnitza & $\begin{array}{l}\text { Hochschule für Ver- } \\
\text { waltung und Finanzen, } \\
\text { Ludwigsburg }\end{array}$ & Verwaltung \\
\hline 3.4.-30.6. 2017 & Marco David & Hochschule des & Verwaltung \\
\hline & Schwarz & Bundes, Brühl & \\
\hline 3. 4. -12.5 .2017 & Eric Veyel & Universität Heidelberg & Frühe Neuzeit \\
\hline 3. 4. -12.5 .2017 & Jonas Nachtsheim & Universität Marburg & Musikgeschichte \\
\hline 15. 5.-23. 6. 2017 & Sandra Funck & Universität Göttingen & Zeitgeschichte \\
\hline 26. 6.-4. 8. 2017 & Elia Di Fonzo & Universität Trento & Zeitgeschichte \\
\hline 26. 6.-4. 8. 2017 & Nastasia Tietze & Universität Weimar & Musikgeschichte \\
\hline 28. 8.-6. 10. 2017 & Maike Jung & $\begin{array}{l}\text { Universität Saar- } \\
\text { brücken }\end{array}$ & Zeitgeschichte \\
\hline 4. 9.-13. 10. 2017 & $\begin{array}{l}\text { Benedikt } \\
\text { Liermann }\end{array}$ & Universität Mainz & Frühe Neuzeit \\
\hline 1. 10.-31. 12. 2017 & Hanna Röper & $\begin{array}{l}\text { Hochschule des } \\
\text { Bundes, Brühl }\end{array}$ & Verwaltung \\
\hline 9. 10.-17. 11. 2017 & $\begin{array}{l}\text { Gregor Christians- } \\
\text { meyer }\end{array}$ & Universität Florenz & Frühe Neuzeit \\
\hline 9. 10.-17. 11. 2017 & $\begin{array}{l}\text { Philipp } \\
\text { Landgrebe }\end{array}$ & Universität Kassel & Mittelalter \\
\hline 20. 11.-29. 12. 2017 & $\begin{array}{l}\text { Franziska } \\
\text { Kleybolte }\end{array}$ & Universität München & Mittelalter \\
\hline 20. 11.-29. 12. 2017 & $\begin{array}{l}\text { Hanna } \\
\text { Wichmann }\end{array}$ & Universität Rostock & Mittelalter \\
\hline 20. 11.-19.12. 2017 & Jens Röschlein & $\begin{array}{l}\text { Humboldt Universität } \\
\text { Berlin }\end{array}$ & Bibliothek \\
\hline
\end{tabular}

Das Institut förderte im Rahmen seines Stipendiatenprogramms zahlreiche Doktoranden/-innen sowie Forschungsvorhaben der Habilitations- bzw. Post-DocPhase. Dieses Programm erfreute sich auch im Jahr 2017 großer Nachfrage. Die Stipendien wurden zu den Bewerbungsterminen 30. 6. 2016 und 15. 2. 2017 über die Internet-Plattform H-Soz-u-Kult, auf der Website des DHI Rom und der Max Weber Stiftung sowie über den Institutsnewsletter ausgeschrieben. Es wurden 33 Stipendien bewilligt, davon gingen 10 an Promovierte von italienischen Universitäten. Von den 23 Stipendien an Doktoranden und Post-Docs deutscher Universitäten entfielen 21 auf Promotions- und 2 auf Post-Doc-Projekte.

Im Jahr 2017 wurden $145900 €$ für Stipendien ausgegeben. Insgesamt wurden 91 Stipendienmonate vergeben, so dass die durchschnittlich gewährte Stipendiendauer ca. 2,75 Monate beträgt. Die Stipendiaten/-innen wurden bei der Vorbereitung und während ihres Aufenthaltes in Italien durch das DHI unterstützt und begleitet. Darüber hinaus wurden ihre Projekte in Mittwochsvorträgen oder Verandagesprächen diskutiert. 


\section{Bewilligte Stipendien}

\section{Mittelalter}

Daniel Baumgartner (München): Bayerische Gefolgsleute der Staufer im Königreich Sizilien

Sabrina Blank (Wuppertal): Die Nichtjudizierbarkeit der prima sedes. Ursprung, Akzeptanz und Umsetzung im Spiegel der Papstwahlen

Ignacio García Lascurain Bernstorff (München): Die Athleten und der Vikar Christi: Eine Untersuchung zur Entwicklung der bilateralen Beziehungen zwischen dem Heiligen Stuhl und dem Johanniterorden in Spätmittelalter und Früher Neuzeit (1353-1503)

Anahita Ghanavati (Marburg): Johannes XXIII. (1410-1415) und seine Petenten

Janina Krüger (Trier): Die Wirtschaftsstrukturen Süditaliens unter Karl I. und Karl II. von Anjou (1266-1309)

Dr. Alberto Luongo (Rom): Aspetti storico-militari della crociata italiana di Giovanni XXII (1321-1324)

Dr. Stefano Mang anaro (Leipzig): Tra i due Imperi e le due Chiese: Argiro di Bari e la sua mediazione longobardo-bizantina negli anni dello scisma (1040-1068)

Dr. Sebastian Roebert (Leipzig): ... talem et tantam potestatem qualis et quanta a domino nobis est comissa. Funktionen und Wirkungen der Königin in der Krone Aragón am Beispiel Eleonore von Sizilien (1349-1375)

Sebastian Schaarschmidt (Chemnitz): Königtum und Krieg in der Stauferzeit

Friederike Maria Schnack (Kiel): Handlungsspielräume geistlicher Herrschaft im Mittelalter. Das Beispiel der Bischöfe von Minden

Dr. Bernhard Schirg (Berlin): Der Humanist und die Mäzenatin. Die Frühwerke Mario Equicolas (ca. 1470-1525) als Schlüssel zum Hofe Isabella d'Estes

Raphael Stepken (Berlin): Panegyrik, Sartire, Kommentar? Der Commentarius des Enea Silvio Piccolomini zu Antonio Beccadellis De dictis et factis Alfonsi regis (1456)

Jaron Sternheim (München): Argument und Strategie im Rigaer Erzbistumsstreit (1480-1483)

Beate Umann (Jena): Das Nepolitaner Bischofsbuch. Römische und neapolitanische Geschichtsschreibung im Widerspiel

\section{Frühe Neuzeit}

Dr. Marco Albertoni (Rom): Le colonne infami nelle repubbliche di Venezia e Genova. Per un'indagine preliminare su un sistema di condanna tra arte, giustizia e memoria pubblica (XVI-XVIII secolo) 
Dr. Maria Teresa Fattori (Innsbruck): La schiavitù nella politica missionaria e nella pastorale della Curia Romana tra XVI e XVIII secolo

Dr. Roberto Fiorentini (Rom): Il ruolo del cardinale Carlo Pio di Savoia juniore come protettore del Sacro romano Impero

Markus Laufs (Bonn): Ein diplomatisches „Weltwunder“. Praktiken und Friedensvermittlung von Vervins bis Rijswijk (1598-1697)

Dr. Chiara Petrolini (Wien): Orientalisti tra Roma e Vienna: Il caso di Sebastian Tengnagel (1573-1636)

\section{Neueste und Zeitgeschichte}

Felix Bohr (Göttingen): Die Kriegsverbrecherlobby. Offene und verdeckte Hilfe aus der Bundesrepublik Deutschland für die NS-Täter Herbert Kappler und die „Vier von Breda“ (1949-1989)

Lars Döpking (Hamburg): Zur Genese des italienischen Steuerstaats. Extraktion, Fiskus und Demokratie in Italien, 1946 bis heute

Swantje Ernst (Tübingen): Arbeit im Schatten der Diktatur. Eine rechtsvergleichende Untersuchung der faschistischen und nazionalsozialistischen Arbeitsgesetzgebung (1926-1939)

Dr. Anna Grillini (Bologna): Il prezzo della fuga dalla guerra. L'autolesionismo nelle carte dell'Archivio dell'Ufficio storico dello Stato Maggiore dell'Esercito

Alexander Hilpert (Saarbrücken): Der Betrüger Heinrich Schaeffer (1837-1884) zwischen Nation und Region. Untersuchung zu Kunst, Kriminalität und Politik in Deutschland, Italien und Frankreich des 19. Jh.

Marius Hirschfeld (Trier): Der Archäologe und Wissenschaftsmanager Ludwig Curtius als exemplarischer Bildungsbürger

Michael Malchereck (Jena): Gabriele Mucchi (1899-2002) - Eine transnationale Intellektuellengeschichte zwischen Kommunismus und Kunst

Anna Katharina Pieper (Mainz): Katholischer (Anti-)Kolonialismus? Der Vatikan, katholische Medien und die europäische Expansionspolitik um 1900

Dr. Matteo Stefa nori (Rom): Ebrei stranieri a Roma (1933-1944)

\section{Musikgeschichte}

Dr. Elena Abbado (Florenz): Contatti e influsso della scena musicale romana sulla fortuna dell'oratorio a Firenze: dalla comune tradizione pre-oratoriale all'oratorio centone

Giuseppina Crescen zo (Weimar): Die italienische geistliche Kantate im 18. Jahrhundert - Exemplifiziert an ausgewählten Themen und Beispielen 
Dr. Giacomo Gibertoni (Bologna): Politica e patronage nel soggiorno romano (1706-1707) di Francesco Maria Pico, ultimo duca della Mirandola: un itinerario di ricerca fra storia politica e storia musicale

Daniel Görlich (Frankfurt am Main): „... das man nicht das machen kann, was man will ...“. Giuseppe Verdis vier Schiller-Opern und das Verhältnis zwischen Oper und Drama

Frédérique Ren no (Freiburg): Modernisierung und Europäisierung des deutschsprachigen weltlichen Liedes zwischen 1570 und 1650

\section{Haushalt, Verwaltung}

Im Berichtsjahr standen dem DHI Rom 4776 T€ zur Verfügung, die tatsächlichen Ausgaben belaufen sich auf 5154 T€. Das Defizit in Höhe von 378 T€ konnte teilweise mit der Einbringung von Overheadmitteln in Höhe von $52 \mathrm{~T} €$ gedeckt werden. Der Rest wird entweder aus Mitteln der Geschäftsstelle übernommen oder muss aus dem Haushalt 2018 bestritten werden.

Die Personalausgaben stellen wie in den Vorjahren den größten Ausgabenposten mit $3541 \mathrm{~T} €$ dar, die Mehrausgaben gegenüber dem Soll des Teilwirtschaftsplans betragen 557 T€; ein Trend, der sich in den Vorjahren entwickelt hat und weiterhin anhält.

Zur Förderung des wissenschaftlichen Nachwuchses wurden 180 T€ investiert.

Im Zuge der Reorganisation der Liegenschaftsverwaltung (vgl. auch Bericht IT) wurde die technische Bestandsaufnahme der Liegenschaft abgeschlossen und auf dieser Grundlage ein Masterplan für die Entwicklung der gesamten Liegenschaft erstellt. Dieser reflektiert unter anderem die Bedürfnisse der im Prozess der Umorganisation befindlichen Bibliothek, schließt ein auf die Anforderungen des Wissenschaftsbetriebs zugeschnittenes Raum- und Funktionskonzept ein (v.a. im Hinblick auf öffentliche Bereiche wie Konferenzräume und Atrium) und berücksichtigt die aktuellen gesetzlichen Auflagen (z. B. barrierefreier Zugang, Erdbebensicherheit etc.). Nach einer abschließenden technisch-ökonomischen Machbarkeitsstudie wurde ein Antrag auf Bereitstellung der nötigen Sondermittel zur Umsetzung des Masterplans, wie auch der benötigten Haushaltsmittel zur Instandsetzung insbesondere der technischen Anlagen, dem Stiftungsrat im November 2017 vorgestellt und von diesem positiv zur Kenntnis genommen. Die Stiftung hat Gespräche mit dem BMBF diesbezüglich aufgenommen.

Die Reorganisation des Eventmanagements auf eine softwarebasierte Lösung ist abgeschlossen (siehe hierzu auch der Bericht der IT-Abteilung). Der zum Jahresbeginn 2017 stiftungsweite Wechsel des Gehaltsdienstleisters in Deutschland ist auch am DHI Rom erfolgreich umgesetzt. Die im Rahmen der Zuwendungsprüfung 2016 empfohlene elektronische Inventarisierung wurde Anfang 2017 mit der Implementierung einer entsprechenden Software umgesetzt. Die Verwaltung hat insgesamt drei 
Beamtenanwärter/-innen des gehobenen nichttechnischen Dienstes in der dreimonatigen berufspraktischen Phase II ausgebildet.

\section{Informations- und Kommunikationstechnologie}

Neben dem Arbeitsschwerpunkt der wissenschaftlichen Datenverarbeitung (vgl. S. XXVIII) war das Jahr 2017 in der IT-Abteilung geprägt durch die umfassende Neustrukturierung der Bibliothek und die im Vorjahr gemeinsam mit der Verwaltungsleitung eingeleitete Reorganisation des Liegenschaftsmanagements. Mit Blick auf die enge Verzahnung von IT-Technik und baulicher Infrastruktur und angesichts der Vielzahl der anstehenden Sanierungs- und Baumaßnahmen wurde mit der „Building Infrastructure Technology“ ein neuer Arbeitsbereich definiert, der hauptverantwortlich von Niklas Bolli (IT-Abteilung) betreut wird. Niklas Bolli leitete in diesem Rahmen eine detaillierte technische Bestandsaufnahme (Projekt Liegenschaftserhebung für die Bereiche Elektroinstallation, HLS, Brandschutz) und koordinierte die Erarbeitung eines Masterplans für die bauliche Sanierung und Modernisierung der Institutsgebäude und ihrer technischen Infrastruktur. Die Ergebnisse wurden im November 2017 dem Stiftungsrat präsentiert (Prof. Martin Baumeister, Dipl. Ing. Arch. Alexis Sittler) und werden durch die laufende Mitarbeit in der AG Liegenschaft der Max Weber Stiftung auch den Schwesterinstituten zugänglich gemacht (Niklas Bolli, Sandra Heisel).

Mit der Zusammenlegung der beiden Institutsbibliotheken und ihrer Neustrukturierung geht auch eine weitreichende technische Neuausrichtung einher, die in enger Zusammenarbeit zwischen Bibliotheksleitung und IT-Abteilung konzipiert und in Teilschritten bereits umgesetzt wurde. Die zukünftige bibliothekarische Informationsverarbeitung am DHI Rom wird dabei wesentlich durch den Beitritt zum Südwestverbund (SWB) bestimmt. Dies schließt den Umstieg von Allegro-C auf das integrierte Bibliothekssystem Koha ein. Die Katalogisierung erfolgt mittels WinIBW in die PicaVerbunddatenbank. Nachdem der historische Bestand des DHI Rom bereits im römischen Bibliotheksverbund „URBiS Library Network“ verzeichnet war, wurden 2017 auch die musikhistorischen Katalogisate in die Datenbank eingespielt. Abgerundet wurde das technische Maßnahmenpaket durch die Modernisierung der OPAC-Terminals in den Lesesälen und den Aufbau eines neuen Web-Bibliotheksportals auf der Basis eines Confluence-Servers, der im DHI-Netzwerk alle Informationsangebote für die Nutzer/-innen der Bibliothek bündelt. Analog dazu wurde ein weiterer Confluence-Server als interner Wiki- und Teambereich aufgebaut und löst seit Herbst 2017 das alte Intranet ab. Das 2015 initiierte Projekt zum Aufbau eines Kommunikationsund Veranstaltungs-Managementsystems auf der Basis der Software CRM COBRA Pro wurde zwischenzeitlich in den Echtbetrieb überführt. Die Web-Serviceportale und Datenbanken stehen den verantwortlichen Mitarbeiter/-innen, Referenten/-innen, externen Mitorganisatoren/-innen sowie Veranstaltungsteilnehmern/-innen seit Jah- 
resbeginn zur Verfügung. Ein Newslettermodul wurde im Jahresverlauf entwickelt und geht Anfang 2018 online. Im internen Betrieb bündelt das neue System die abteilungsübergreifenden Arbeitsabläufe, löst vormals uneinheitliche und fehleranfällige Verfahren ab und optimiert so die Zusammenarbeit von Verwaltung, Öffentlichkeitsarbeit und Sekretariaten. Das System wird 2018 um ein Redaktionsmodul für das Rezensionswesen der QFIAB erweitert.

Das DHI Rom arbeitet bei allen beschriebenen Maßnahmen stets im engen Verbund mit der Geschäftsstelle Bonn und den Schwesterinstituten der Max Weber Stiftung. Dies schlug sich im Berichtszeitraum in einigen neuen Kooperationen nieder wie z.B. einem Remote-Backupverfahren zwischen DHI London und DHI Rom und dem Ausbau der vom DHI Rom betreuten Videokonferenzcloud der Max Weber Stiftung (Telex Comunicazioni/Starleaf). Die Stiftung dokumentiert ihre IT-Verfahren in einem gemeinschaftlichen IT-Rahmenkonzept, das 2018 zur Aktualisierung ansteht. Wichtige lokale IT-Partner für das Institut sind der italienische Hochschulverbund CINECA und die Deutsche Schule Rom (DSR). Über eine dedizierte Glasfaserstrecke ist das Institut mit der DSR vernetzt und nutzt diese Architektur für einen gegenseitigen Fallback-Betrieb als Teil des IT-Sicherheitskonzepts.

Nach Ablauf des Mandats seines Vorgängers wurde Niklas Bolli von den Mitarbeitern/-innen zum Beauftragten für Arbeitssicherheit gewählt. Jan-Peter Grünewälder wurde seitens des Direktors zum IT-Sicherheitsbeauftragten bestellt und nimmt das Sprecheramt des IT-Arbeitskreises der Stiftung wahr, aktuell gemeinsam mit Eugen Bastron (DHI Moskau).

\section{Personal und Gremien}

\section{Personal und Institutsaufgaben}

Direktor

Prof. Dr. Martin Baumeister

Stellvertretende Direktoren

PD Dr. Lutz Klinkhammer (ab 1. 3. 2017)

Prof. Dr. Alexander Koller

Assistentin des Direktors:

Dott.ssa Monika Kruse

Verwaltung

Verwaltungsleiterin:

Sandra Heisel 
Veranstaltungsmanagement, allgemeine Verwaltungsaufgaben:

Paola Fiorini

Personalsachbearbeitung, Beschaffung:

Zarah Marcone

Buchhaltung, Reisekosten:

Elisa Ritzmann

Innerer Dienst:

Alessandra Costantini

Dott.ssa Eva Grassi

Alessandro Silvestri

Giuseppe Tosi

Guido Tufariello

Öffentlichkeitsarbeit:

Dr. Claudia Gerken

Dr. Kordula Wolf

Wissenschaftliche Übersetzung:

Dr. Gerhard Kuck

Wissenschaftliche Datenverarbeitung:

Dr. Jörg Hörnschemeyer

Informations- und Kommunikationstechnologie:

Niklas Bolli

Jan-Peter Grünewälder

Bibliothek (seit Juni 2017 zusammengelegt)

Leitung:

Patricia Kern, M.A., M.A. LIS (ab 1. 7. 2017)

Wissenschaftlicher Mitarbeiter:

Dr. Thomas Hofmann

Bibliothekarinnen:

Dipl.-Bibl. Elisabeth Dunkl

Dipl.-Bibl. Christina Ruggiero

Dipl.-Bibl. Liane Soppa 
Bibliotheksmitarbeiter/-innen:

Martina Confalonieri

Antonio La Bernarda

Dott.ssa Christine Streubühr

Roberto Versaci

\section{Wissenschaftliche Mitarbeiter/-innen}

Mittelalter:

Dr. Christian Alexander Neumann (ab 1. 10. 2017)

Dr. Andreas Rehberg

Dr. Kordula Wolf

Repertorium Germanicum:

Dr. Jörg Voigt

Frühe Neuzeit:

Dr. Andreea Badea

Prof. Dr. Alexander Koller

PD Dr. Heinrich Lang (bis 31. 8. 2017)

Dr. Carlo Taviani (bis 15. 9. 2017)

19. und 20. Jahrhundert:

PD Dr. Lutz Klinkhammer

Dr. Carolin Kosuch

DFG-Projektmitarbeiterin „Ferdinand Gregorovius: Poesie und Wissenschaft. Gesammelte deutsche und italienische Briefe“

Dr. Angela Steinsiek (ab 1. 11. 2017)

Projektmitarbeiter „Le Udienze di Mussolini““

Dr. Amedeo Osti Guerrazzi (bis 30. 6. 2017)

\section{Musikgeschichtliche Abteilung}

Dr. Markus Engelhardt (Leiter)

Dr. Sabine Ehrmann-Herfort (Stellvertretende Leiterin)

Dr. Richard Erkens 
Projektmitarbeiterin „Topoi der Friedensdarstellung in der italienischen Kantate (17.18. Jahrhundert)“

Dr. Chiara Pelliccia

Gastwissenschaftler/-in:

Dr. Nicole Kramer (bis 30. 6. 2016)

PD Dr. Daniel Hedinger (ab 1. 9. 2017)

\section{Ämter im Personalbereich}

Personalrat:

Jörg Hörnschemeyer (Vorsitz)

PD Dr. Lutz Klinkhammer (bis 28. 2. 2017)

Bibl.-Dipl. Liane Soppa

Dr. Jörg Voigt (ab 13. 12. 2017)

Sprecher der Wissenschaftlichen Mitarbeiter/-innen:

Dr. Richard Erkens

PD Dr. Lutz Klinkhammer (Vertreter bis 28. 2. 2017)

Dr. Jörg Voigt (Vertreter ab 24. 4. 2017)

Sprecher der Ortskräfte:

Antonio La Bernarda

Guido Tufariello

Vertrauensfrau des Instituts:

Susanne Wesely

\section{Redaktionen}

Bibliothek des Deutschen Historischen Instituts Rom (De Gruyter):

Dr. Kordula Wolf

Ricerche dell'Istituto Storico Germanico di Roma (Viella):

Dr. Kordula Wolf (bis 30. 7. 2017)

Dr. Andreas Rehberg (ab 1. 8. 2017)

QFIAB:

Prof. Dr. Alexander Koller

Redaktion: Susanne Wesely (ab 1. 3. 2017) 
Bibliographische Informationen:

Dr. Lutz Klinkhammer (Gesamtkoordination)

Redaktion: Dott.ssa Eva Grassi, Dr. Gerhard Kuck, Susanne Wesely

Online Publikationen des Deutschen Historischen Instituts in Rom:

Dr. Kordula Wolf

Analecta musicologica (Bärenreiter):

Dr. Sabine Ehrmann-Herfort

Dr. Markus Engelhardt

Concentus musicus (Bärenreiter):

Dr. Markus Engelhardt

\section{Wissenschaftlicher Beirat}

Prof. Dr. Maria Pia Alberzoni, Università Cattolica del Sacro Cuore Mailand Prof. Dr. Thomas Betzwieser, Goethe-Universität Frankfurt am Main Prof. Dr. Patrizia Dogliani, Università degli Studi di Bologna Prof. Dr. Irmgard Fees, Ludwig-Maximilians-Universität München Prof. Dr. Nikolas Jaspert, Ruprecht-Karls-Universität Heidelberg (Vorsitzender) Prof. Dr. Bernd Roeck, Universität Zürich Prof. Dr. Petra Schulte, Universität Trier Prof. Dr. Günther Wassilowsky, Goethe-Universität Frankfurt am Main (stv. Vorsitzender)

Prof. Dr. Clemens Zimmermann, Universität des Saarlandes Saarbrücken

\section{Freundeskreis des DHI}

Vorsitzender: Dr. Eberhard J. Nikitsch (Mainz)

Stellvertreter: Dr. Kai-Michael Sprenger (Mainz)

Schatzmeister: Dr. Stephan Kern (Mainz)

Martin Baumeister 